\title{
Ortalama Su Seviyesi Değişimlerinin Taş Dolgu Kıyı Koruma Yapılarının Tasarımına ve Performansına Etkisi
}

\author{
Hasan Gökhan GÜLER ${ }^{1}$ \\ Gülizar Özyurt TARAKCIOĞLU \\ Cüneyt BAYKAL ${ }^{3}$
}

ÖZ

Gel-git, mevsimsel değişiklikler, dalga kabarması/alçalması, fırtına kabarması ve küresel ısınmaya bağlı su seviyesi değişimleri sonucunda ortalama su seviyesinde gözlenen değişimler, taş dolgu kıyı koruma yapılarının tasarımlarının ve performanslarının değerlendirilmesi ile doğrudan ilgilidir. Bu tip yapılar için en kritik su seviyesi, yaygın olarak en yüksek su seviyesi tanımı ile kullanılmaktadır. Ancak, Kıyı Yapıları Planlama ve Tasarım Teknik Esasları'nda [1] koruma yapısında kullanılacak taşların kütlelerinin belirlenmesi için en kritik su seviyesinin en düşük su seviyesi ile en yüksek su seviyesi arasında ortaya çıkabileceği belirtilmiştir. Bu çalışmada taş dolgu kıyı koruma yapılarının tasarım derinliğinin belirlenmesinde kullanılan farklı yaklaşımların koruma tabakası taş kütlesi ile serbest kret kotuna olan etkisi incelenmiştir. Bu amaçla Karadeniz, Ege Denizi ve Akdeniz'de birer proje alanı seçilmiş ve bu projelerdeki yapıların ekonomik ömürleri boyunca gözlenebilecek tüm su seviyelerinde koruma tabakası taş kütlesi ile serbest kret kotu hesaplanmıştır. Seçilen projeler için daha düşük su seviyelerinde daha yüksek su seviyelerine göre \%60’a varan oranlarda daha büyük taş kütlesi bulunmuştur. Çalışma sonuçları, en yüksek su seviyesinden daha kritik bir su seviyesinin, düşük su seviyesi ile en yüksek su seviyesi arasındaki herhangi bir su seviyesinde de oluşabileceğine örnek oluşturmaktadır. Buna bağlı olarak, seçilen kritik su seviyesi değeri ile koruma tabakası taş kütlesi hesaplama yöntemlerinin ilişkisi tartışılmış ve yapının ekonomik ömrü boyunca oluşabilecek tüm su seviyelerinin tasarım derinliği belirlenirken göz önünde bulundurulması önerilmiştir.

Anahtar Kelimeler: Ortalama su seviyesi, taş dolgu, koruma tabakası, dalga aşması, iklim değişikliği.

\footnotetext{
Not: Bu yazı

- Yayın Kurulu'na 27 Temmuz 2018 günü ulaşmıştır. 30 Mayıs 2019 günü yayımlanmak üzere kabul edilmiştir.

- 31 Temmuz 2020 gününe kadar tartışmaya açıktır.

- https://dx.doi.org/10.18400/tekderg.448489

1 Orta Doğu Teknik Üniversitesi, İnşaat Mühendisliği Bölümü, Ankara - goguler@metu.edu.tr https://orcid.org/0000-0002-9015-4470

2 Orta Doğu Teknik Üniversitesi, İnşaat Mühendisliği Bölümü, Ankara - gulizar@metu.edu.tr https://orcid.org/0000-0001-8327-3300

3 Orta Doğu Teknik Üniversitesi, İnşaat Mühendisliği Bölümü, Ankara - cbaykal@metu.edu.tr https://orcid.org/0000-0002-8514-2758
} 


\section{ABSTRACT Effect of Mean Water Level Variations on the Design and Performance of Rubble-
Mound Coastal Protection Structures}

Variations in mean water level such as tides, seasonal variations, wave set-up/set-down, storm surge and sea level rise due to global warming are directly related to design and performance evaluation of rubble-mound coastal structures. The highest water level is generally considered as the most critical water level for this type of structures. However, Coastal Structures Planning and Design Manual [1] states that the most critical water level can be observed in between the lowest water level and the highest water level. In this study, the effects of different approaches used in selecting design water level on the mass of the armor stone and the free crest height are investigated. Three project sites are selected in the Black Sea, Aegean Sea and the Mediterranean Sea, and the mass of armor stones and the free crest height are calculated at each water level that might be observed during the economic lifetime of these structures. For the selected projects, up to $60 \%$ of bigger mass of armor stones are found at lower water levels compared to higher water levels. The results of this study examplifies that the most critical water level can be observed in between the lowest water level and highest water level. In addition, the relation of the most critical water level and the calculation methods of the mass of armor stones are discussed, and it is suggested to assess all the water levels that might occur during the economic life of the structure.

Keywords: Mean water level, rubble mound, armor layer, wave overtopping, climate change.

\section{GİRIş}

Kıyı yapılarının ekonomik ömürleri boyunca meydana gelen kısa ve uzun dönemli su seviyesi değişimleri bu yapıların tasarımı ve performanslarının değerlendirilmesinde önem taşımaktadır. Tasarım derinliği kıyı yapılarının önündeki dalga özelliklerini doğrudan etkilediğinden, kıyı yapılarının tasarımında kullanılan en önemli parametrelerden biridir. T.C. Ulaştırma, Denizcilik ve Haberleşme Bakanlığı Altyapı Yatırımları Genel Müdürlüğü (AYGM) tarafından hazırlanan Kıyı Yapıları Planlama ve Tasarım Teknik Esasları'nda [1] tasarım derinliği gel-git, mevsimsel değişiklikler, dalga kabarması/alçalması, rüzgâr kabarmas1/alçalması, barometrik ve Coriolis etkileri ve küresel ısınmaya bağlı su seviyesi değişimleri gibi kısa ve uzun dönemli su seviyesi değişimlerine bağlı olarak tanımlanmaktadır. Ülkemizde yaygın bir şekilde kullanılan taş dolgu kıyı koruma yapılarının tasarımında genel yaklaşım, hem taş dolgu kıyı koruma yapılarının koruma tabakasını oluşturan taşların boyutlarının belirlenmesinde hem de yapının ömrü boyunca işlevselliğinin kesintiye uğramaması için serbest kret kotunun belirlenmesinde "en kritik su seviyesinin" tasarım derinliği olarak kullanılmasıdır. Dünya ölçeğinde yaygın bir şekilde kullanılan "Kıyı Koruma Şartnamesi (Shore Protection Manual)" [2], "Hidrolik Mühendisliğinde Kaya Kullanımı (The Use of Rock in Hydraulic Engineering)" [3] gibi tasarım şartnamelerinde taş dolgu kıyı koruma yapılarının tasarımında en kritik su seviyesi, bu tip yapıların ömrü boyunca karşılaş1labilinecek en yüksek su seviyesi olarak düşünülmektedir. En yüksek su seviyesi ise, ortalama su seviyesinde meydana gelen değişimlerin deterministik olarak ortalama su seviyesine eklenmesi ile bulunmaktadır. Ülkemizde kıyı yapılarının tasarımında kullanılan esasların "2.1.2. Tasarım Derinliği” başlıklı bölümünde ise, taş dolgu 
dalgakıranların serbest kret kotlarının belirlenmesinde en kritik su seviyesinin yapının ömrü boyunca karşılaşılabilinecek en yüksek su seviyesi olduğu, koruma yapısında kullanılacak taşların kütlelerinin belirlenmesinde ise en kritik su seviyesinin en düşük su seviyesi ile en yüksek su seviyesi arasında ortaya çıkabileceği belirtilmiştir [1]. Bu çalışmada öncelikli olarak yukarıda ifade edilen ve yaygın şekilde kullanılan tasarım esaslarındaki kritik su seviyesi hakkındaki yaklaşım farklılıklarının tasarım üzerindeki etkisinin incelenmesi amaçlanmaktadır. Diğer bir deyişle, AYGM [1]'de taş dolgu kıyı koruma yapılarının koruma tabakasının tasarımı için yapılan "en kritik su seviyesinin her zaman en yüksek seviyesi olmayabileceği" değerlendirmesinin tasarım üzerindeki sonuçları tartışılmaktadır.

$\mathrm{Bu}$ çalışmanın amacına yönelik olarak tasarım derinliğinin hem koruma tabakasında kullanılan taşların kütlelerinin belirlenmesine hem de serbest kret kotunun belirlenmesine etkisi ülkemizi çevreleyen Karadeniz, Ege Denizi ve Akdeniz'de seçilen üç proje alanı için gerçek tasarım koşulları kullanılarak incelenmiştir. Bu incelemede, koruma tabakası taş kütlesi ve serbest kret kotu yapının ekonomik ömrü boyunca görülebilecek her su seviyesi için hesaplanmıştır. Tasarım derinliği hesaplanırken yukarıda ifade edilen ortalama su seviyesi değişiklikleri göz önüne alınmıştır. Taş dolgu dalgakıranların koruma tabakalarında kullanılan taşların kütlelerinin belirlenmesi ile ilgili olan uygulamalarda Hudson [2] formülü ile CIRIA vd. [3] tarafindan önerilen Van der Meer [4] ve Van Gent vd. [5] formüllerinin birlikte kullanıldığ yaklaşım kullanılmıştır. Serbest kret kotu ise EurOtop [6] tarafından önerilen dalga aşması formülü ile hesaplanmıştır. Taş dolgu dalgakıranların tasarımı için seçilen yaklaşımlar AYGM [1] tarafından da önerilmektedir. Bu hesaplamalar ile daha düşük su seviyelerinde $\% 60$ 'a varan oranda daha büyük taş kütlesi değerlerinin ortaya çıabileceği seçilen proje alanları için yapılan pratik mühendislik uygulamalarıyla örneklenmiştir. Böylece taş dolgu kıyı koruma yapılarının koruma tabakalarının tasarımında en yüksek su seviyesinin her zaman en kritik su seviyesi olmayabileceği gösterilmiştir.

\section{ORTALAMA SU SEVIYESINDE MEYDANA GELEN KISA VE UZUN DÖNEMLİ DEĞIŞIMLER}

Ortalama su seviyesinde meydana gelen değişimler Türkiye kıyıları boyunca Harita Genel Komutanlığı'na (HGK) bağlı Türkiye Ulusal Deniz Seviyesi İzleme Sistemi (TUDES) tarafından bu çalışmanın hazırlandığı tarihte 22 mareograf istasyonu ile ölçülmektedir. HGK tarafından mareograf istasyonlarında ölçülen veriler kullanılarak düşey referans değerleri hesaplanmaktadır [7]. Kıyı mühendisliği uygulamalarında sıklıkla ihtiyaç duyulan ortalama su seviyesi ve bu su seviyesindeki değişimler ile ilgili çalışmalarda, referans değerlerinin doğru bir şekilde kullanılması büyük önem taşımaktadır. AYGM [1] ortalama su seviyesini belirli bir dönem boyunca deniz seviyesinin ortalama yüksekliği olarak tanımlamakta ve pratik olarak bu değerin bir yılın ortalama deniz seviyesi olarak alınmasını önermektedir. Ortalama su seviyesinde meydana gelen kısa ve uzun dönemli değişimler ile bu çalışma kapsamında bu değişimler için kullanılan değerler ve ilgili kabuller aşağıda verilmektedir.

\subsection{Gelgit}

Gelgitler Ay'ın, Dünya'nın ve Güneş'in hareketlerinin ortak etkisi sonucu oluşan su seviyesi iniş çıkışları olarak tanımlanmaktadır [8]. Türkiye kıyıları mikro gelgit bölgesi sınıfına 
girmekte ve gelgitler genel itibariyle çok etkili olmamaktadır. Alpar vd. [9]'a göre Türkiye kıyıları boyunca gelgit 10 ile $50 \mathrm{~cm}$ arasında değişmektedir. Bu çalışmada gelgit genliği bütün Türkiye kıyılarında ortalama bir değer olarak ortalama su seviyesinden $\pm 15 \mathrm{~cm}$ olarak kabul edilmiştir.

\subsection{Mevsimsel Değişimler}

Ortalama su seviyesi denizler, ırmaklar ve yağış miktarının etkilediği su dengesindeki değişiklikler sebebiyle mevsimsel olarak değişmektedir. Mevsimsel su seviyesi değişimleri Alpar vd. [9] tarafindan verilen değerlere bağlı kalınarak ortalama su seviyesinden Karadeniz için $\pm 9,5 \mathrm{~cm}$ (toplamda $19 \mathrm{~cm}$ ), Ege Denizi için $\pm 4 \mathrm{~cm}$ (toplamda $8 \mathrm{~cm}$ ) ve Akdeniz için $\pm 8,5$ cm (toplamda $17 \mathrm{~cm}$ ) olarak alınmıştır.

\subsection{Dalga Kabarması/Alçalması}

Dalga kabarması/alçalması firtına koşulları sebebiyle oluşan ortalama su seviyesi değişimlerindendir. Goda [10], dalga kabarmasını dalgaların yakın kıyıda kırılmalarından dolayı oluşan yarı-doğrusal su seviyesi yükselmesi olarak tanımlamaktadır. Kıyıya doğru dalga kabarmasının oluştuğu durumlarda diğer yönde, dalgaların kırıldığı sörf bölgesinde gözlemlenen ortalama su seviyesindeki düşüş ise dalga alçalması olarak tanımlanmaktadır. $\mathrm{Bu}$ çalışmada dalga kabarması/alçalması, dalga dönüşümü çalışmaları için kullanılacak sayısal modelin içinde hesaplanmaktadır.

\subsection{Fırtına Kabarması/Alçalması: Rüzgâr Kabarması/Alçalması ile Barometrik ve Coriolis Etkileri}

Fırtına koşullarında rüzgârın su yüzeyine etki ettirdiği kayma gerilmesi sebebiyle su yüzeyinde bir eğim oluşmaktadır. Rüzgârların kıyıya doğru esmesi durumunda kıyıda ortalama su seviyesinde yükselme, rüzgâr kabarması, karadan açığa doğru esmesi durumunda ise kıyıda ortalama su seviyesinde azalma, rüzgâr alçalması gözlenir [3].

Rüzgâr kabarmasının alçak basınç sistemleri ve Dünya'nın ekseni etrafındaki hareketinden kaynaklanan Coriolis kuvvetinin etkileriyle ve dalga kabarması ile birleşerek oluşturduğu ortalama su seviyesi yükselmesi ise fırtına kabarması olarak adlandırılmaktadır. Öte yandan, yüksek basınç sistemleri de ortalama su seviyesinde alçalmalara yol açabilmektedir [11]. Bununla birlikte, Coriolis etkisi ortalama su seviyesinde kıyı şeridinin konumlanışına göre yükselme veya alçalmaya yol açabilmektedir [12].

Fırtına kabarması ve alçalması fırtına koşullarında ortalama su seviyesinde meydana gelen yükselme ve alçalmaları ifade etmektedir. Fırtına kabarması ve alçalmasının bileşenleri rüzgâr kabarması/alçalması, barometrik ve Coriolis etkiler olarak alınmaktadır. Bu çalışmada fırtına kabarmasının değeri, literatürde benzeri çalışmalarda [13] kullanıldığı şekilde derin deniz belirgin dalga yüksekliğinin $\left(\mathrm{H}_{\mathrm{s} 0}\right)$ \%10'u kabul edilerek gelgit seviyesine eklenmektedir $[13,14,15]$. Diğer bir deyişle, bu çalışmada firtına kabarması ortalama su seviyesinden $\pm 0,1 \mathrm{H}_{\mathrm{s} 0}$ olarak alınmıştır. 


\subsection{Küresel Isınmaya Bağlı Su Seviyesi Değişimleri}

Küresel ısınmaya bağlı olarak gerçekleşen su seviyesi değişimleri, kıyı yapıları uzun ekonomik ömür için tasarlandığg göz önüne alındığında ortalama su seviyesi değişimlerinin en önemli bileşeni olarak karşımıza çıkmaktadır. Türkiye İklim Değişikliği 6. Bildirimi’nde de küresel ısınmaya bağlı deniz seviyesi değişimlerine ve bunların kıyılarımızdaki muhtemel etkilerine dikkat çekilmektedir [16]. Küresel ısınmaya bağlı olarak rüzgâr hızlarında ve dalga yüksekliklerinde de değişimler beklenmektedir. Örneğin Karadeniz'de belirgin dalga yüksekliklerinde yükselme eğilimi olduğu gösterilmiştir [17]. Ortalama su seviyesinde gerçekleşen bu değişim doğrudan tasarım derinliğini etkilediği için hem yeni kıyı yapılarının tasarımında hem de mevcut yapıların performanslarının değerlendirilmesinde göz önüne alınmalıdır. Küresel ısınmaya bağlı su seviyesi değişimleri araştırmaları mareograf istasyonlarından alınan su seviyesi ölçümlerine bağlı olarak yapılabileceği gibi iklim değişikliği projeksiyonlarına bağlı olarak da yapılabilmektedir. Küresel ısınmadan kaynaklı su seviyesi artışının Türkiye kıyılarında da görüldüğü mareograf istasyonlarından alınan verilerin incelendiği çeşitli çalışmalarda ortaya konulmuştur [18-25]. Bununla birlikte Vousdoukas vd. [26] tarafindan Avrupa kıyıları boyunca ekstrem su seviyelerinin incelendiği çalışmada, Karadeniz ve Doğu Akdeniz'de iklim değişikliğine bağlı su seviyesinin arttığı gösterilmiş, farklı iklim değişikliği senaryolarına göre bu değişimin miktarı tahmin edilmiştir. Mevcut çalışma kapsamında yapılan uygulamalarda, Hükümetlerarası İklim Değişikliği Paneli (Intergovernmental Panel on Climate Change) tarafindan hazırlanan 5. Değerlendirme Raporu'nda verilen RCP8.5 iklim değişikliği senaryosuna [27] bağlı olarak Vousdoukas vd. [26] tarafından hesaplanan küresel ısınmaya bağlı su seviyesi değişimi değerleri kullanılmıştır. Tercih edilen iklim değişikliği senaryosu olan RCP8.5 ile 2081-2100 yılları arasındaki dönemde, global ortalama sıcaklığın 1850-1900 yılları arasındaki seviyeden 3,2-5,4 ${ }^{\circ} \mathrm{C}$ daha yüksek olacağı öngörülmektedir. Bu senaryoya göre yapılan hesaplamalarda 2000 yılından 2100 yılına kadar Karadeniz'de ve Doğu Akdeniz'de ortalama $80 \mathrm{~cm}$ küresel iklim değişikliğine bağlı su seviyesi yükselmesi olması beklenmektedir. Sonuç olarak bu çalışmada 100 yıllık dönemde tüm Türkiye kıyılarında küresel ısınmaya bağlı su seviyesi yükselmesinin $80 \mathrm{~cm}$ olacağı kabul edilmiştir.

\section{YÖNTEM}

\subsection{Yöntemin Ana Hatları}

Tasarım derinliği taş dolgu kıyı koruma yapılarının ekonomik ömrü boyunca oluşabilecek en kritik koşullara karşılık gelmektedir. Tasarım derinliği belirlenirken yapı önü ortalama su seviyesi ve Bölüm 2'de tanımlanan ortalama su seviyesi değişimleri göz önüne alınmaktadır. Bunun için öncelikle yapının ekonomik ömrü boyunca beklenebilecek en düşük su seviyesi ile en yüksek su seviyesi belirlenir. Daha önce de belirtildiği üzere alışagelmiş tasarım düşüncesinde en yüksek su seviyesi en kritik su seviyesi olarak düşünülmekte ve tasarım derinliği olarak seçilmektedir. Ancak bu çalışmada çeşitli örnekler ile gösterileceği üzere, koruma tabakasında kullanılacak taş kütlelerinin hesaplanmasında en kritik su seviyesinin en düşük su seviyesi ile en yüksek su seviyesi arasında bir başka değer alması mümkündür. $\mathrm{Bu}$ sebeple, taş dolgu kıyı koruma yapısının ömrü boyunca karşılaşılabilecek su seviyelerinin her biri göz önüne alınarak en kritik tasarım derinliğinin belirlenmesi ve tasarım parametrelerinin hesaplanması gerekmektedir. Bu çalışmada önerilen yöntemde, tasarım 
derinliği en düşük su seviyesinden başlayarak en yüksek su seviyesine kadar seçilen miktarlarda deterministik olarak arttırılarak, her bir tasarım derinliği için taş kütlesi, serbest kret kotu gibi temel tasarım çıktıları hesaplanarak tartışılmaktadır. Bununla birlikte, taş dolgu yapıların topuk tasarımında hem topukta kullanılması gereken taş kütlesi hem de geometri açısından en düşük su seviyesinin esas alınması gerekmektedir. Ancak bu çalışma koruma tabakasında kullanılması gereken taş kütlesi ve serbest kret kotu hesaplamalarına odaklandığından, topuk tasarımı ile ilgili bir değerlendirme/hesaplama sunulmamıştır.

\subsection{Dalga Dönüşümü Çalışmalarında Kullanılan Yöntemler}

Taş dolgu kıyı koruma yapılarının koruma tabakasında kullanılan taşların kütlelerinin belirlenebilmesi için kullanılan Hudson [2] yaklaşımı düzenli dalgalar için verildiğinden dalgaların yapı önündeki kırılma koşulları ve buna bağlı olarak yapı önündeki kırılan veya kırılmayan dalga yükseklikleri doğrusal sığlaşma, doğrusal kırınım ve derinlik-limitli kırılma yaklaşımı kullanılarak belirlenmektedir [28].

Öte yandan koruma tabakasındaki taşların kütlelerinin belirlenebilmesi için kullanılan Van der Meer [4] ve Van Gent vd. [5] yöntemleri ile dalga aşması hesaplarında kullanılan EurOtop [6] yaklaşımı düzensiz dalgalar için verilmiştir. Düzensiz dalgaların yapı önüne taşınabilmesi için bu çalışmada Baykal [29] tarafından MATLAB ortamında geliştirilen 1Boyutlu NSW isimli sayısal model kullanılmıştır. NSW'da temel olarak derinlik boyunca değişen dalga yüksekliklerini bulabilmek için enerji denge denklemi çözülmekte; bununla birlikte, dalga etkisiyle oluşan dalga kabarması ve alçalmasının ortalama su seviyesinde meydana getirdiği değişiklikleri bulabilmek için doğrusal olmayan sı̆̆ su denklemleri çözülmektedir. Düzensiz dalgaların yapı önündeki dalga yüksekliklerinin bulunmasına ek olarak, bu çalışmada kullanılan bütün yaklaşımlar için dalga kabarması NSW sayısal modeli yardımıyla bulunmaktadır.

NSW sayısal modeli yakın kıyı dalga yüksekliğinin bulunabilmesi için faz-ortalamalı bir yaklaşım kullanmaktadır ve hesaplanan parametrelerin bir firtına boyunca sabit olduğunu kabul etmektedir. Düzensiz bir batimetri üzerinde dalga dönüşümü çalışmalarını doğrusal dalga sığlaşması, doğrusal dalga kırınımı ve derinlik tarafından kontrol edilen dalga kırılması kullanarak gerçekleştirmektedir. Gel-git, rüzgâr kabarması, atmosferik basınç ve Coriolis etkileri gibi ortalama su seviyesinde meydana gelen değişimlerin etkisi bu sayısal modele girilen ortalama su seviyesi ile yansitılmaktadır. Taban sürtünmesi ve deniz köpüklenmesinden kaynaklanan enerji kaybı hesaplamalara yansıtılmamaktadır. Öte yandan, doğrusal olmayan sı̆̆ su denklemleri 1-Boyutlu olarak çözülerek ortalama su seviyesindeki dalga kabarması/alçalmasından kaynaklı değişiklikler çözüme yansıtılmaktadır. Doğrusal olmayan sı̆̆ su denklemlerinin çözümünde ana katkı gerilme akısı (radiation stress) olarak kabul edilmekte, yatay taşınım ve yayılım etkileri ve taban sürtünme terimleri dâhil edilmemektedir. 1-Boyutlu çözüm gerçekleştirilmesi nedeniyle düzgün ve paralel eş derinlik eğrileri kabul edilerek, diğer boyutların etkisi göz önüne alınmamaktadır.

NSW sayısal modeli Baykal [29, 30] ile Baykal vd. [31] tarafindan birçok farklı veri seti kullanılarak kalibre edilmiş ve doğrulanmıştır. NSW sayısal modelinin yukarıda ifade edilen kabuller altında çözdüğü denklemler ve çözüm yönteminin ayrıntıları, çalışmanın "Ek A: NSW Sayısal Modeli” bölümünde verilmiştir. 


\section{3. Çalışmada Kullanılan Tasarım Formülleri}

Taş dolgu kıyı koruma yapılarının koruma tabakasında kullanılan taşların kütlelerinin belirlenebilmesi için AYGM [1] tarafından önerilen Hudson [2] yaklaşımı ile CIRIA vd. [3] tarafından önerilen Van der Meer [4] ve Van Gent vd. [5] yaklaşımlarının birlikte kullanıldığı yöntem kullanılmıştır. Bununla birlikte, taş dolgu kıyı koruma yapılarının serbest kret kotunun belirlenmesinde belirleyiciliği bulunan dalga aşması hesaplamalarında ise EurOtop [6] tarafindan ortaya konulmuş yöntem kullanılmıştır.

Düzenli dalgalar için verilen Hudson [2] yaklaşımı Denklem 1 ile gösterilmiştir.

$$
M_{50}=\frac{\rho_{t} H^{3}}{\left(\rho_{t} / \rho_{s}-1\right)^{3} K_{D} \cot (\alpha)}
$$

Denklem 1'de $M_{50}$ ortalama taş kütlesini, $\rho_{t}$ taşların özgül kütlesini, $\rho_{s}$ deniz suyunun özgül kütlesini, H tasarım dalga yüksekliğini, $K_{D}$ stabilite katsayısını ve $\alpha$ yapı şev açısını belirtmektedir. AYGM [1] ve CERC [2] tasarım dalga yüksekliğini, bir firtına boyunca yapı önüne ulaşan dalgaların en yüksek \%10'unun ortalaması $\left(H_{1 / 10}\right)$ olarak kullanılmasını önermektedir. Yapı önünde tasarım dalgasının kırılma özelliklerine göre bu dalga yüksekliği belirlenmektedir. Bu çalışmada yapılan tüm hesaplamalarda taşların özgül kütlesi 2,650 t/ $\mathrm{m}^{3}$, beton blokların özgül kütlesi 2,400 t/m $\mathrm{m}^{3}$ ve deniz suyunun özgül kütlesi $1,025 \mathrm{t} / \mathrm{m}^{3}$ olarak alınmıştır.

CIRIA vd. [3] tarafından taş dolgu kıyı koruma yapılarının koruma tabakasında kullanılan taşların kütlelerinin belirlenmesi için önerilen yöntemde derin deniz koşullarında Van der Meer [4] yöntemi, sı̆̆ su koşullarında ise Van Gent vd. [5] yönteminin kullanılması önerilmektedir. Burada yapı önü su seviyesinin $(h)$, yapı önü belirgin dalga yüksekliğine $\left(H_{s}\right)$ oranının $\left(h / H_{s}\right)$ 3'ten büyük olması olarak, sığ su ise bu oranın $\left(h / H_{s}\right)$ 3'ten küçük olması olarak tanımlanmaktadır. Van der Meer [4] yönteminin uygulanmasında öncelikli olarak dalgaların kırılma tipi sıçrayarak kırılan dalga (plunging) koşulu veya kabararak kırılan dalga (surging) koşulundan biri seçilerek belirlenmektedir. Kırılma tipinin belirlenebilmesi için Denklem 2'de verilen kritik kırılma parametresi $\left(\xi_{k}\right)$, Denklem 3 yardımıyla ve ortalama dalga periyodu $\left(T_{m}\right)$ dikkate alınarak hesaplanan kırılma parametresi $\left(\xi_{m}\right)$ ile karşılaştırılmaktadır.

$$
\begin{aligned}
& \xi_{k}=\left[6,2 P^{0,31} \sqrt{\tan \alpha}\right]^{\frac{1}{P+0,5}} \\
& \xi_{m}=\frac{\tan \alpha}{\sqrt{\frac{2 \pi}{g} \frac{H_{s}}{T_{m}^{2}}}}
\end{aligned}
$$

Denklem 2 ve Denklem 3'te $P$ değeri Van der Meer [4] tarafından önerilen geçirimliliği, $\alpha$ şev eğimini, $g$ yerçekimi ivmesini, ve $H_{s}$ yapı önündeki belirgin dalga yüksekliğini 
göstermektedir. Ortalama dalga periyodu $\left(T_{m}\right)$ dikkate alınarak hesaplanan kırılma parametresinin $\left(\xi_{m}\right)$ kritik kırılma parametresinden $\left(\xi_{k}\right)$ küçük olduğu durumda sıçrayarak (plunging) kırılan dalgalar için verilen Denklem 4, büyük veya eşit olması durumunda kabararak (surging) kırılan dalgalar için verilen Denklem 5'in kullanılması önerilmektedir.

$$
\begin{aligned}
& \xi_{m}<\xi_{k}, \frac{H_{s}}{\Delta D_{50}}=6,2 P^{0,18}\left(\frac{S}{\sqrt{N}}\right)^{0,2}\left(\xi_{m}\right)^{-0,5} \\
& \xi_{m} \geq \xi_{k}, \frac{H_{s}}{\Delta D_{50}}=1,0 P^{-0,13}\left(\frac{S}{\sqrt{N}}\right)^{0,2} \sqrt{\cot \alpha}\left(\xi_{m}\right)^{P}
\end{aligned}
$$

Denklem 4 ve Denklem 5 'te $\Delta$ göreceli özgül kütleyi, $D_{50}$ taşların medyan nominal kübik çapını, $S$ hasar miktarını ve $N$ firtına süresince oluşan dalgaların sayısını göstermektedir.

Van Gent vd. [5] yaklaşımında ise Van der Meer [4] yaklaşımına benzer şekilde öncelikli olarak dalgaların kırılma tipi sıçrayarak kırılan dalga koşulu veya kabararak kırılan dalga koşulundan biri seçilerek belirlenmektedir. Kırılma tipinin belirlenebilmesi için Denklem 6'da verilen kritik kırılma parametresi $\left(\xi_{k}\right)$, Denklem 7 yardımıyla hesaplanan ve spektral dalga periyodu $\left(T_{m-1,0}\right)$ dikkate alınarak hesaplanan kırılma parametresi $\left(\xi_{m-1,0}\right)$ ile karşılaştırılmaktadır.

$$
\begin{aligned}
& \xi_{k}=\left[\frac{8,4}{1,3} P^{0,31} \sqrt{\tan \alpha}\right]^{\frac{1}{P+0,5}} \\
& \xi_{m-1,0}=\frac{\tan \alpha}{\sqrt{\frac{2 \pi}{g} \frac{H_{s}}{T_{m-1,0}^{2}}}}
\end{aligned}
$$

Spektral dalga periyodu $\left(T_{m-1,0}\right)$ dikkate alınarak hesaplanan kırılma parametresinin $\left(\xi_{m-1,0}\right)$, kritik kırılma parametresinden $\left(\xi_{k}\right)$ küçük olduğu durumda sıçrayarak kırılan dalgalar için verilen Denklem 8, büyük veya eşit olması durumunda kabararak kırılan dalgalar için verilen Denklem 9'un kullanılması önerilmektedir.

$$
\begin{aligned}
& \xi_{m-1,0}<\xi_{k}, \frac{H_{s}}{\Delta D_{50}}=8,4 P^{0,18}\left(\frac{S}{\sqrt{N}}\right)^{0,2}\left(\frac{H_{s}}{H_{\% 2}}\right)\left(\xi_{m-1,0}\right)^{-0,5} \\
& \xi_{m-1,0} \geq \xi_{k}, \frac{H_{s}}{\Delta D_{50}}=1,3 P^{-0,13}\left(\frac{S}{\sqrt{N}}\right)^{0,2}\left(\frac{H_{s}}{H_{\% 2}}\right) \sqrt{\cot \alpha}\left(\xi_{m-1,0}\right)^{P}
\end{aligned}
$$


Denklem 8 ve Denklem 9'da $H_{\% 2}$ bir firtına için aşılma olasılı̆̆ı \%2 olan dalgaların yüksekliğini göstermektedir. Çalışma kapsamında bu değer sığ suda Battjes ve Groenendijk [32] tarafindan verilen yöntemle bulunmaktadır.

Bu çalışmada hasar parametresi (S), Van der Meer [4]'e göre hasar başlangıç değeri olarak kabul edilen $S=2$ olarak kullanılmıştır. Bununla birlikte, AYGM [1] firtına süresi bilgisi olmadığı koşullarda dalga sayısının 3000 olarak alınmasını önermektedir. Ayrıca, Van Gent vd. [5] formülleri en yüksek 3000 dalga altında yapılan testlerle ortaya koyulmuştur. Bu nedenlerle, bu çalışma boyunca yapılan hesaplamalarda dalga sayısı 3000 olarak kabul edilmiştir. Van der Meer [4] ve Van Gent vd. [5] yaklaşımlarının her ikisinde de kullanılan geçirimlilik (P) katsayısı, ülkemizde sıklıkla kullanılan dalgakıran tip kesiti göz önüne alınarak 0,4 olarak kabul edilmiştir. Bu tip kesitinde koruma tabakasında iki sıra taş kullanılmakta, geçirimli çekirdek ile koruma tabakası arasında geçirimli filtre tabakası bulunmaktadır.

Dalga aşması çalışmalarında AYGM [1] tarafindan EurOtop [6] yaklaşımının kullanılması önerilmektedir. EurOtop [6] yaklaşımında taş dolgu kıyı koruma yapıları için "ortalama değer" ve "tasarım" yaklaşımları olmak üzere iki farklı grupta denklemler önerilmektedir. $\mathrm{Bu}$ çalışmada tasarıma yönelik yaklaşım kullanılarak hesaplamalar gerçekleştirilmiştir. Denklem 10'da dik şevler (1:2'den 4:3'e kadar olan şevler) için verilen formül, Denklem 11 'de ise yatık şevler (1:2'den yatık şevler) için verilen formül sunulmaktadır. Yatık şevler söz konusu olduğunda, Denklem 11'e ek olarak Denklem 10 kullanılarak da hesaplamalar yapılması ve Denklem 11 ile hesaplanan değerlerin Denklem 10 ile hesaplanan değerlerden büyük olması durumunda, Denklem 10'nun baz alınması önerilmektedir.

$$
\begin{aligned}
& \frac{\mathrm{q}}{\sqrt{\mathrm{g \textrm {H } _ { \mathrm { s } } ^ { 3 }}}}=0,1035 \exp \left[-\left(1,35 \frac{\mathrm{R}_{\mathrm{c}}}{\mathrm{H}_{\mathrm{s}} \gamma_{\mathrm{f}} \gamma_{\beta}}\right)^{1,3}\right] \\
& \frac{\mathrm{q}}{\sqrt{\mathrm{g} \mathrm{H}_{\mathrm{s}}^{3}}}=\frac{0,026}{\sqrt{\tan \alpha}} \gamma_{\mathrm{b}} \xi_{\mathrm{m}-1,0} \exp \left[-\left(2,5 \frac{\mathrm{R}_{\mathrm{c}}}{\xi_{\mathrm{m}-1,0} \mathrm{H}_{\mathrm{s}} \gamma_{\mathrm{b}} \gamma_{\mathrm{f}} \gamma_{\beta} \gamma_{\mathrm{v}}}\right)^{1,3}\right]
\end{aligned}
$$

Denklem 10 ve 11 'de $q$ izin verilen birim uzunluktaki dalga aşma debisini, $R_{c}$ serbest kret kotunu, $\gamma_{\mathrm{f}}$ pürüzlülük azaltma katsayısını, $\gamma_{\beta}$ açıyla gelen dalgalar için düzeltme katsayısını, $\gamma_{\mathrm{b}}$ basamaklı yapılar için düzeltme katsayısını ve $\gamma_{\mathrm{v}}$ şev sonunda yer alabilecek duvar için verilen düzeltme katsayısını göstermektedir.

$\mathrm{Bu}$ çalışma kapsamında yapılan dalga aşması hesaplamalarında, izin verilen birim dalga aşması debi miktarı 10 lt/s/m olarak alınmış ve bu değere göre serbest kret kotundaki değişim hesaplanmıştır. 


\section{4. ÖRNEK UYGULAMALAR}

Bu çalışmada sunulan örnek uygulamalar Karadeniz, Ege Denizi ve Akdeniz'de bulunan üç farklı proje alanında yapılan "danışmanlık projeleri” verileri kullanılarak yapılmıştır. Projelerin sözleşme hususları sebebiyle proje alanları, projelerin ayrıntıları ve tasarlanmış/inşa edilmiş kesitler ile ilgili bilgiler açık bir şekilde sunulamamaktadır. Fakat bu uygulamalarda kullanılan tasarım parametreleri çalışmanın akışı içerisinde verilmiştir. Çalışmanın devamında Karadeniz, Ege Denizi ve Akdeniz'den seçilen bu üç örnek sırasıyla Proje A, Proje B ve Proje C olarak anılmaktadır. Proje A'da bir taş dolgu kıyı koruma yapısı, Proje B ve Proje C'de ise bir taş dolgu dalgakıran çalışılmıştır. Seçilen proje alanlarına özgü olarak gerçekleştirilen bu hesaplamalarda kullanılan parametrelerin ileriki dönemlerde bu bölgelerde gerçekleştirilebilecek başka çalışmalar için doğrudan kullanılması uygun değildir. Her proje alanı için güncel literatür araştırması yapılması gerekmektedir.

Proje A, B ve C örnek uygulamalarında, tasarım dalga özellikleri proje yöresinde bulunan meteoroloji ölçüm istasyonlarından elde edilen rüzgâr hızı ve yönü verileri ile The European Centre for Medium-Range Weather Forecasts (ECMWF, Avrupa Orta Vadeli Hava Tahminleri Merkezi) tarafından proje alanına yakın bir noktada alınan rüzgâr hızı ve yönü verileri karşılaştırmalı bir şekilde çalışılmıştır. Yapılan karşılaştırmalar sonucu tercih edilen veri kaynakları kullanılarak elde edilen sonuçlar bu çalışmada doğrudan sunulmakta, verilerin analizi ile ilgili tartışmalar makalenin konusu içerisinde olmadığı için burada verilmemektedir. Buna göre Proje A ve Proje B için derin deniz dalga özellikleri ECMWF tarafından proje alanına yakın bir nokta için deniz seviyesinden $10 \mathrm{~m}$ yüksekte verilen rüzgâr hızı ve yönü verisi kullanarak tahmin edilmiştir. Proje C için ise Yumurtalık Meteoroloji İstasyonu'ndan alınan ve deniz seviyesinden $10 \mathrm{~m}$ yüksekte verilen rüzgâr hızı ve yönü verisi Hsu [33] tarafından önerilen yöntemle karadan denize taşındıktan sonra kullanılmıştır. Dalga özelliklerinin tahmini ODTÜ İnşaat Mühendisliği Deniz Mühendisliği Araştırma Merkezi'nde geliştirilen “Derin Deniz Dalga Tahmin Matematik Modeli, W61” kullanılarak yapılmıştır [34, 35]. Bu modelde belirli bir yönden gelen firtına içindeki her saatte oluşmuş saatlik rüzgâr hız ve yön bilgileri ve bu yönlere ait etkin kabarma uzunlukları kullanılmaktadır. Buna göre rüzgârın deniz yüzeyinde oluşturduğu sürtünme kuvveti ile oluşan enerjinin zaman içinde oluşumu, gelişimi ve sönümlenmesi hesaplanmakta ve saatlik ortalama belirgin dalga özellikleri fırtına süresi boyunca belirlenmektedir. Tahmin edilen saatlik dalga özellikleri kullanılarak yapılan en büyük değer dalga istatistiği çalışmalarıyla seçilen yineleme periyoduna sahip dalgaların özellikleri Goda [10] tarafından verilen yönteme uygun olarak FT-1 (Gumbel), FT-II, Log-Normal ve Weibull olasılık dağılımları değerlendirilerek belirlenmiştir. Bu çalışmada sunulan örnek uygulamaların hepsinde yineleme periyodu 100 yıl olarak seçilmiştir. Örnek uygulamalarda proje alanı batimetrisi incelenerek ortalama taban eğimleri bulunmuştur. Ortalama taban eğiminin derin deniz sınırından kıyı çizgisine kadar sabit bir şekilde devam ettiği kabul edilmiştir. Dalga dönüşümü hesaplamalarının yapıldığı NSW sayısal modelinde ise hesaplama ağı aralığ $5 \mathrm{~m}$ olarak alınmıştır. Bu değer, çözüm sonuçlarının hesaplama ağı aralığından bağımsız olmasını sağlayacak şekilde belirlenmiştir. Ortalama su seviyesinde meydana gelen değişimlerin taş dolgu kıyı koruma yapılarının tasarımına etkisi Bölüm 3'te açıklanan yöntem kullanılarak hesaplanmış ve uygulamaların hepsinde kıyı koruma yapısının gövde kesitleri göz önüne alınmıştır. Hudson [2] yaklaşımı ile hesaplanan ocak taşı büyüklüklerinin Proje A ve Proje C uygulamalarında doğal limitlerin üzerinde olması sebebiyle her üç uygulama bölgesinde küp ve dolos beton bloklar için de hesaplamalar gerçekleştirilmiştir. Küp beton bloklar, ocak 
taşlarına benzer şekilde kendi kütleleriyle yapı stabilitesini sağladıkları; dolos beton bloklar ise kendi kütlelerine ek olarak kitlenme özellikleriyle de yapı stabilitesini arttırdıkları için tercih edilmişlerdir. Benzeri şekilde serbest kret kotu hesaplamalarında da ocak taşlarının yanısıra küp ve dolos beton bloklar için işlemler yapılmıştır. Proje A için küp ve dolos beton bloklar ile yapılan uygulamalarda diğer projelerden farklı bir yol izlenmiştir. Proje A'da seçilen kesitin şev eğimi ocak taşı kullanılarak 1:5 olarak belirlenmiştir. Ancak, küp ve dolos beton bloklar uygulamalarında 1:5 gibi yatık bir eğim kullanılmamaktadır. Bu sebeple, Proje A için küp ve dolos beton bloklar ile yapılan uygulamalarda şev eğimi 1:2 alınmıştır. Öte yandan CIRIA vd. [3] yaklaşımı sadece ocak taşları için verildiğinden, bu yaklaşımla ilgili hesaplamalar ocak taşlarıyla sınırlı tutulmuştur. Her üç proje alanı için kullanılan tasarım parametreleri Tablo 1'de verilmektedir.

Tablo 1 - Örnek uygulamalarda kullanılan tasarım parametreleri

\begin{tabular}{|c|c|c|c|}
\hline Parametreler & $\begin{array}{c}\text { Proje } \\
\text { A }\end{array}$ & $\begin{array}{c}\text { Proje } \\
\text { B }\end{array}$ & $\begin{array}{c}\text { Proje } \\
\text { C }\end{array}$ \\
\hline Yineleme Periyodu (yıl) & 100 & 100 & 100 \\
\hline Derin Deniz Belirgin Dalga Yüksekliği, $\mathrm{H}_{\mathrm{s} 0}(\mathrm{~m})$ & 8,00 & 4,05 & 5,7 \\
\hline Derin Deniz Pik Dalga Dikliği, $\mathrm{S}_{0}$ & 0,0341 & 0,0377 & 0,0397 \\
\hline Derin Deniz Yaklaşma Açısı, $\alpha_{0}\left(^{\circ}\right)$ & 52,5 & 22,5 & 0.0 \\
\hline Taban Eğimi, m & $1: 30$ & $1: 10$ & $1: 30$ \\
\hline Dalga Sayısı, N & \multicolumn{3}{|c|}{3000} \\
\hline Seçilen Kesitin Önünde Ölçülen Su Derinliği (m) & 11,5 & 11,0 & 16,0 \\
\hline \multicolumn{4}{|l|}{ Ortalama Su Seviyesinde Meydana Gelen Değişimler } \\
\hline Gel-Git (m) & $\pm 0,150$ & $\pm 0,150$ & $\pm 0,150$ \\
\hline Mevsimsel Değişimler (m) & $\pm 0,095$ & $\pm 0,040$ & $\pm 0,085$ \\
\hline Firtına Kabarması (m) & $\pm 0,800$ & $\pm 0,405$ & $\pm 0,570$ \\
\hline Küresel Isınmaya Bağlı Su Seviyesi Değişimi (m) & \multicolumn{3}{|c|}{$+0,800$} \\
\hline \multicolumn{4}{|c|}{ Kaba, Köşseli Ocak taşı için Kullanılan Tasarım Parametreleri } \\
\hline Şev Eğimi & $1: 5$ & $1: 2,5$ & $1: 2$ \\
\hline Hudson Stabilite Katsayısı, Kırılmayan Dalgalar ${ }^{1}\left(\mathrm{~K}_{\mathrm{D}}\right)$ & \multicolumn{3}{|c|}{4,0} \\
\hline Hudson Stabilite Katsayıs1, Kırılan Dalgalar ${ }^{1}\left(\mathrm{~K}_{\mathrm{D}}\right)$ & \multicolumn{3}{|c|}{2,0} \\
\hline Geçirimlilik, $\mathrm{P}$ & \multicolumn{3}{|c|}{0,4} \\
\hline Van der Meer Hasar Parametresi, S & \multicolumn{3}{|c|}{2} \\
\hline Pürüzlülük Katsayısı (iki sıra, geçirimli çekirdek) $\left(\gamma_{f}\right)$ & \multicolumn{3}{|c|}{0,40} \\
\hline
\end{tabular}


Ortalama Su Seviyesi Değişimlerinin Taş Dolgu Kıyı Koruma Yapılarının ...

Tablo 1 - Örnek uygulamalarda kullanılan tasarım parametreleri (devamı)

\begin{tabular}{|c|c|c|c|}
\hline Parametreler & $\begin{array}{c}\text { Proje } \\
\text { A }\end{array}$ & $\begin{array}{l}\text { Proje } \\
\text { B }\end{array}$ & $\begin{array}{l}\text { Proje } \\
\text { C }\end{array}$ \\
\hline \multicolumn{4}{|l|}{ Küp Beton Bloklar için Kullanılan Tasarım Parametreleri } \\
\hline Şev Eğimi & $1: 2$ & $1: 2,5$ & $1: 2$ \\
\hline Hudson Stabilite Katsayıs1, Kırılmayan Dalgalar $\left(\mathrm{K}_{\mathrm{D}}\right)$ & 6,5 & 7,5 & 6,5 \\
\hline Hudson Stabilite Katsayısı, Kırılan Dalgalar $\left(\mathrm{K}_{\mathrm{D}}\right)$ & 5,0 & 6,0 & 5,0 \\
\hline Pürüzlülük Katsayısı (iki sıra, düzensiz) $\left(\gamma_{\mathrm{f}}\right)$ & \multicolumn{3}{|c|}{0,47} \\
\hline \multicolumn{4}{|l|}{ Dolos Beton Bloklar için Kullanılan Tasarım Parametreleri } \\
\hline Şev Eğimi & $1: 2$ & $1: 2,5$ & $1: 2$ \\
\hline Hudson Stabilite Katsayıs1, Kırılmayan Dalgalar ${ }^{2}\left(\mathrm{~K}_{\mathrm{D}}\right)$ & \multicolumn{3}{|c|}{31,8} \\
\hline Hudson Stabilite Katsayısı, Kırılan Dalgalar ${ }^{2}\left(K_{D}\right)$ & \multicolumn{3}{|c|}{15,8} \\
\hline Pürüzlülük Katsayısı $\left(\gamma_{\mathrm{f}}\right)$ & \multicolumn{3}{|c|}{0,43} \\
\hline \multicolumn{4}{|c|}{ Dalga Aşması Hesaplamalarında Kullanılan Diğer Tasarım Parametreleri } \\
\hline Basamaklı Yapılar için Düzeltme Katsayısı $\left(\gamma_{\mathrm{b}}\right)$ & \multicolumn{3}{|c|}{1,0} \\
\hline Şev Sonunda Yer Alan Duvar Düzeltme Katsayısı $\left(\gamma_{v}\right)$ & \multicolumn{3}{|c|}{1,0} \\
\hline \multicolumn{4}{|c|}{$\begin{array}{l}\text { 'AYGM [1]' de 1:5 şev eğiminde ocak taşı için verilen bir değer bulunmadığından, } 1: 3 \\
\text { şev eğimi için verilen değerler kullanılarak güvenli tarafta kalınmıştır. }\end{array}$} \\
\hline \multicolumn{4}{|c|}{$\begin{array}{l}{ }^{2} \text { Dolos için } 1: 2 \text { ve } 1: 3 \text { şev eğimlerinde verilen dĕgerler aynı olduğu için, } 1: 2,5 \text { şev ĕgim } \\
\text { için de bu değerler alınmıştır. }\end{array}$} \\
\hline
\end{tabular}

Tablo 1'de verilen parametrelerin daha iyi anlaş1labilmesi için Şekil 1'de örnek bir kesit üzerinde yapısal elemanlar, ortalama su seviyesi (OSS), düşük su seviyesi (DSS) ve yüksek su seviyesi (YSS) gösterilmiştir. Tasarım derinliği YSS ve DSS arasında bir derinlik olarak ortaya çıkabilmektedir.

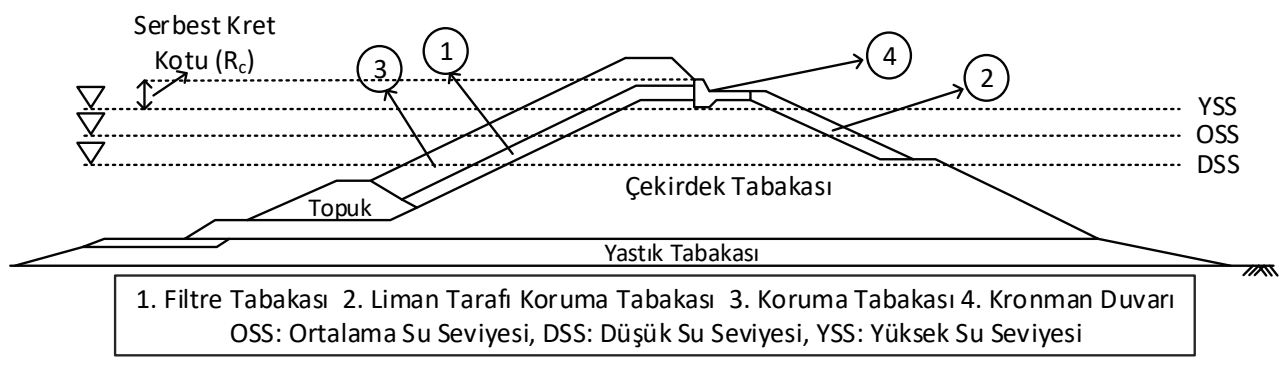

Şekil 1 - Taş Dolgu Dalgakıranlara İlişkin Yapısal Tanımlar (AYGM [1] baz alınarak hazırlanmıştır.) 


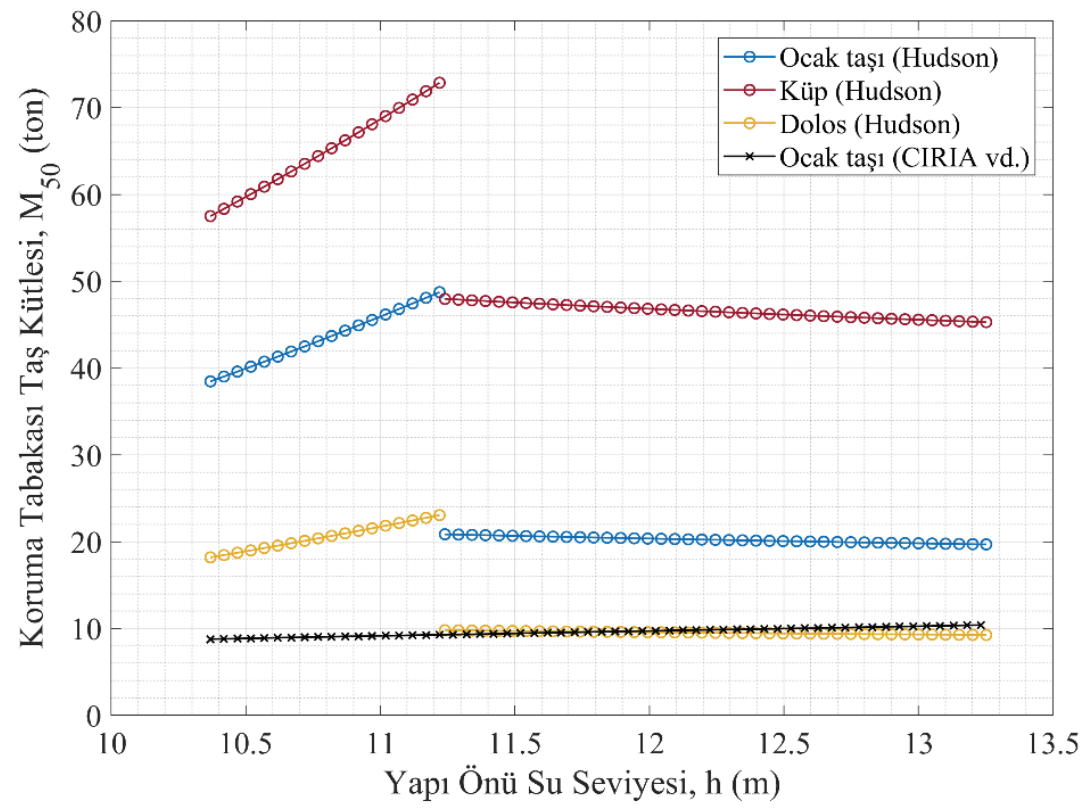

Şekil 2 - Proje A için Hudson [2] ve CIRIA vd. [3] yaklaşımlarıyla hesaplanan koruma taş kütlesinin ile yapı önü su seviyesine göre değişimi

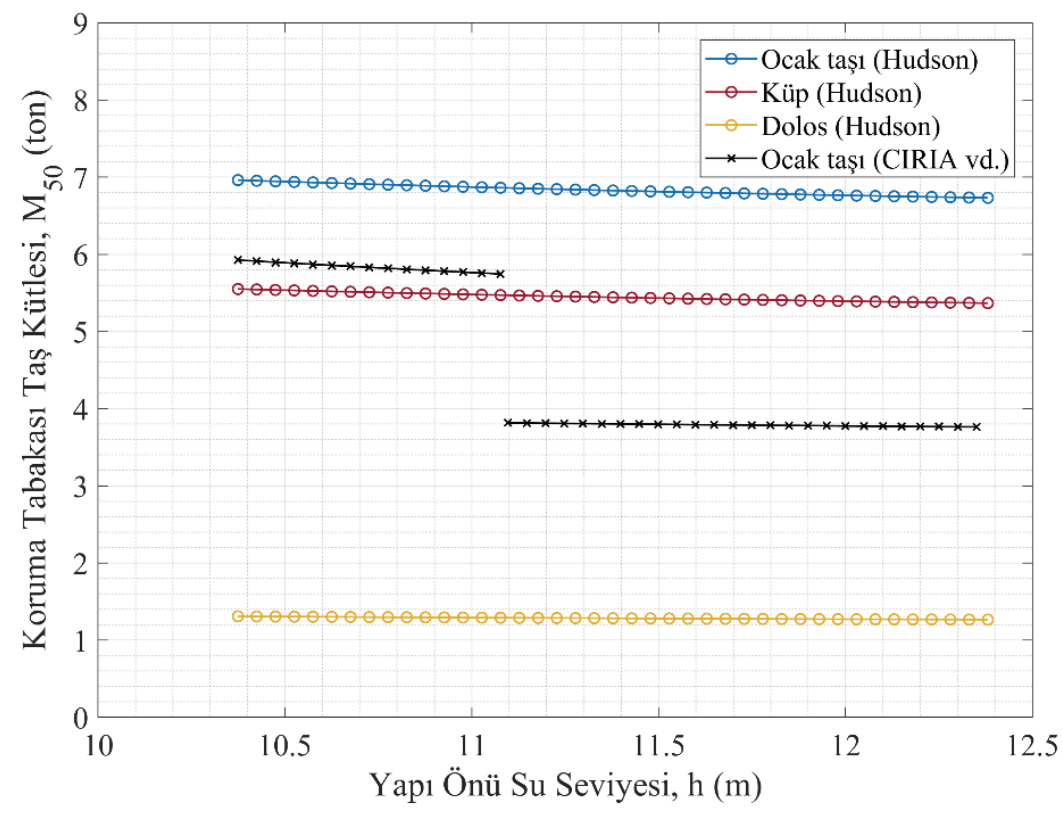

Şekil 3 - Proje B için Hudson [2] ve CIRIA vd. [3] yaklaşımlarıyla hesaplanan koruma taş kütlesinin ile yapı önü su seviyesine göre değişimi 
Ortalama Su Seviyesi Değişimlerinin Taş Dolgu Kıyı Koruma Yapılarının ...

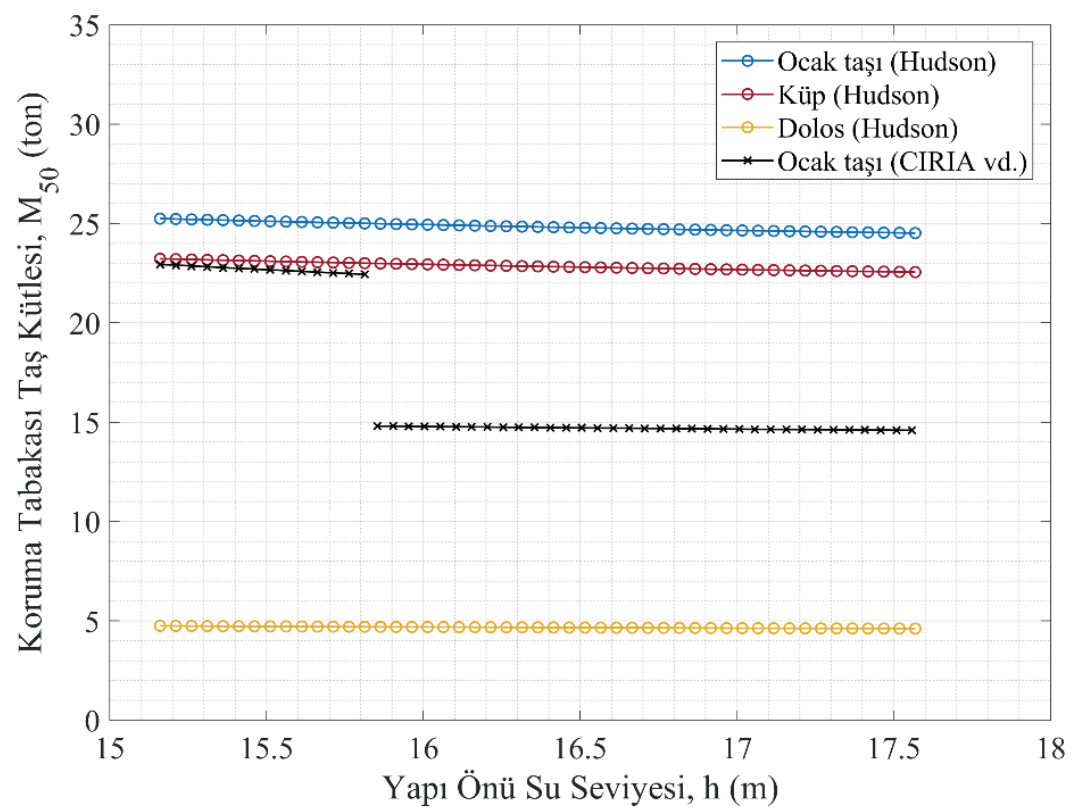

Şekil 4 - Proje C için Hudson [2] ve CIRIA vd. [3] yaklaşımlarıyla hesaplanan koruma taş kütlesinin ile yapı önü su seviyesine göre değişimi

Proje A, Proje B ve Proje C alanları için Tablo 1'de verilen tasarım parametreleri ile Hudson [2] ve CIRIA vd. [3] yaklaşımları kullanılarak ve yapı önü su seviyesi değiştirilerek yapılan koruma tabakası taş kütlesi hesaplamalarının sonuçları sırasıyla Şekil 2, Şekil 3 ve Şekil 4'te verilmektedir.

Şekil 2'de görüleceği üzere Proje A yöresinde Hudson [2] yaklaşımı ve ocak taşı kullanılarak yapılan çalışmalarda taş büyüklükleri doğal ocak taşı büyüklüklerinin üzerindedir. Hudson [2] yöntemi kullanılarak bulunan küp blokların kütleleri şev eğimi daha dik alındıği için Hudson [2] yaklaşımı ile hesaplanan ocak taşı kütlelerinden yüksek değerlerdedir. Küp beton bloklarda ise görece düşük su seviyelerinde 60-70 ton mertebesinde yer alan beton blok büyüklükleri, görece yüksek su seviyelerinde 45-50 ton değerlerine düşmektedir. Dolos beton bloklar için yapılan hesaplamalarda ise görece düşük su seviyelerinde 18-24 ton seviyesindeki beton blok büyüklüklerinin, görece yüksek su seviyesinde yaklaşı 10 ton mertebesinde olduğu görülmektedir. Diğer bir deyişle, düşük su seviyelerindeki beton blok kütleleri yüksek su seviyelerinde beton blok kütlelerine göre \%60'a varan oranlarda daha büyüktür. Sonuç olarak, Proje A yöresinde kullanılan tasarım parametreleri dikkate alındığında Hudson [2] yaklaşımı için daha kritik tasarım koşullarının düşük su seviyelerinde ortaya çıkmaktadır. Bu kesit için yapılan uygulamada, su seviyesi yükseldikçe Hudson [2] yöntemine göre yapının tasarım koşulu kırılan dalgalar koşulundan, kırılmayan dalgalar koşuluna dönmüştür. Diğer bir deyişle, en yüksek su seviyesi bu kesit için en kritik koşul olmamakta, daha düşük su seviyeleri daha kritik tasarım koşulları ortaya çıkarmaktadır. CIRIA vd. [3] yaklaşımı kullanıldığında ise projenin bu kesiti için yapı önü su seviyesi arttıkça koruma tabakasında kullanılması gereken taş kütlesi de artmaktadır. Bu metot göz 
önüne alındığında en kritik koşulun alışılagelmiş tasarım yönteminde olduğu gibi en yüksek su seviyesi olduğu görülmektedir. Bu durumun sebebi ise göz önüne alınan su seviyelerinin o derinlikteki belirgin dalga yüksekliğine oranlarının $\left(\mathrm{h} / \mathrm{H}_{\mathrm{s}}\right)$ tümünün 3 'ten küçük olması ve dolayısıyla CIRIA vd. [3] tarafından önerilen tasarım yaklaşımına göre Van Gent vd. [5] formülünün kullanılması gereken bölgede kalmış olmasıdır.

Şekil 3 incelendiğinde, Proje B yöresi için Hudson [2] yaklaşımı kullanılarak yapılan hesaplamalarda yapının ekonomik ömrü boyunca gözlenebilecek su seviyelerinde kullanılması gereken taş ve beton blok büyüklükleri neredeyse değişmediği görülmektedir. Diğer bir deyişle, tasarım derinliğinin en yüksek su seviyesi veya daha düşük su seviyelerinden birisi olarak alınmasının verilen tasarım parametreleri kullanıldığında projenin bu kesitinde sonuca etkisi önemli olmamaktadır. CIRIA vd. [3] yaklaşımı kullanıldığ 1 durumda ise Şekil 3 'te görülebileceği üzere yapı önü su seviyesi arttıkça koruma tabakasında kullanılması gereken taş kütlesi 5,5-6 ton mertebesinden 3,5-4 ton mertebesine düşmektedir. Yüzdesel olarak bakıldığında bu farklılık \%50’ye karşılık gelmektedir. Bu durumun sebebi su seviyesinin yükseldiği durumlarda yapı önü su seviyesinin yapı önü belirgin dalga yüksekliğine oranının $\left(\mathrm{h} / \mathrm{H}_{\mathrm{s}}\right)$ 3'ten küçükken, 3'ten büyük değerlere geçmesidir. Diğer bir deyişle, CIRIA vd. [3] tarafından önerilen metoda göre düşük su seviyelerinde Van Gent vd. [5] metodu kullanılırken, yüksek su seviyelerinde Van der Meer [4] metodunun kullanılmasından dolayı bu farklılık oluşmaktadır. Sonuç olarak bu yöntemin koruma tabakası taş kütlesi hesaplarında kullanılması durumunda bu kesit ve dalga koşulları için düşük su seviyelerinin daha kritik sonuçlar verdiği görülmüştür.

Şekil 4'e göre, Proje C yöresi için Hudson [2] yaklaşımı kullanılarak hesaplanan ocak taşı büyüklükleri doğal limitlerin üzerindedir. Beton bloklarda ise ortalama su seviyesinin değişiminin bu kesit için taş kütlesine önemli bir etkisinin olmadığı görülmüştür. Proje B için için yapılan örnek uygulamada olduğu gibi, Şekil 4'te görülebileceği üzere bu kesit ve tasarım parametreleri kullanılarak CIRIA vd. [3] yaklaşımına göre yapılan hesaplamalarda yükselen su seviyesi Proje C yöresi için de daha az kritik bir koşul oluşturmuş̧tur. Bu durum görece düşük su seviyelerinde Van Gent vd. [5] yaklaşımı kullanılırken, görece yüksek su seviyelerinde Van der Meer [4] yaklaşımının kullanılması sebebiyle ortaya çıkmaktadır. Fakat Van Gent vd. [5] yöntemiyle hesaplanan ocak taşı büyüklüklerinin doğal limitlerin üzerinde olması, Van der Meer [4] yöntemiyle hesaplanan ocak taşı büyüklüklerinin ise doğal limitlerin sınırında olması (yaklaşık 14 ton) sebepleriyle bu tasarım parametreleri ve kesit için beton blok kullanımının değerlendirilmesi gerekmektedir.

Proje A, Proje B ve Proje C alanları için Tablo 1'de verilen tasarım parametreleri ile EurOtop [6] yaklaşımı kullanılarak ve yapı önü su seviyesi değiştirilerek yapılan serbest kret kotu hesaplamalarının sonuçları sırasıyla Şekil 5, Şekil 6 ve Şekil 7'de verilmektedir.

Şekil 5'te görüldüğü üzere, Proje A yöresinde hem ocak taşı hem de beton bloklar için yapı önü su seviyesi arttıkça serbest kret kotunun değeri artmakta, bir süre sonra serbest kret kotu hesaplamaları için çok küçük olarak değerlendirilebilecek miktarlarda $(1-2 \mathrm{~cm})$ azalmıştır. Dolayısıyla dalga aşması hesaplamalarında bu kesit ve tasarım koşulları için en kritik koşulların en yüksek su seviyesinde hesaplanan değerlere yakın olduğu görülmektedir. Bununla birlikte, pürüzlülük katsayısına bağlı olarak serbest kret kotunun en yüksek değeri küp bloklarda, en düşük değeri ise ocak taşlarında aldığ görülmüştür. 
Ortalama Su Seviyesi Değişimlerinin Taş Dolgu Kıyı Koruma Yapılarının ...

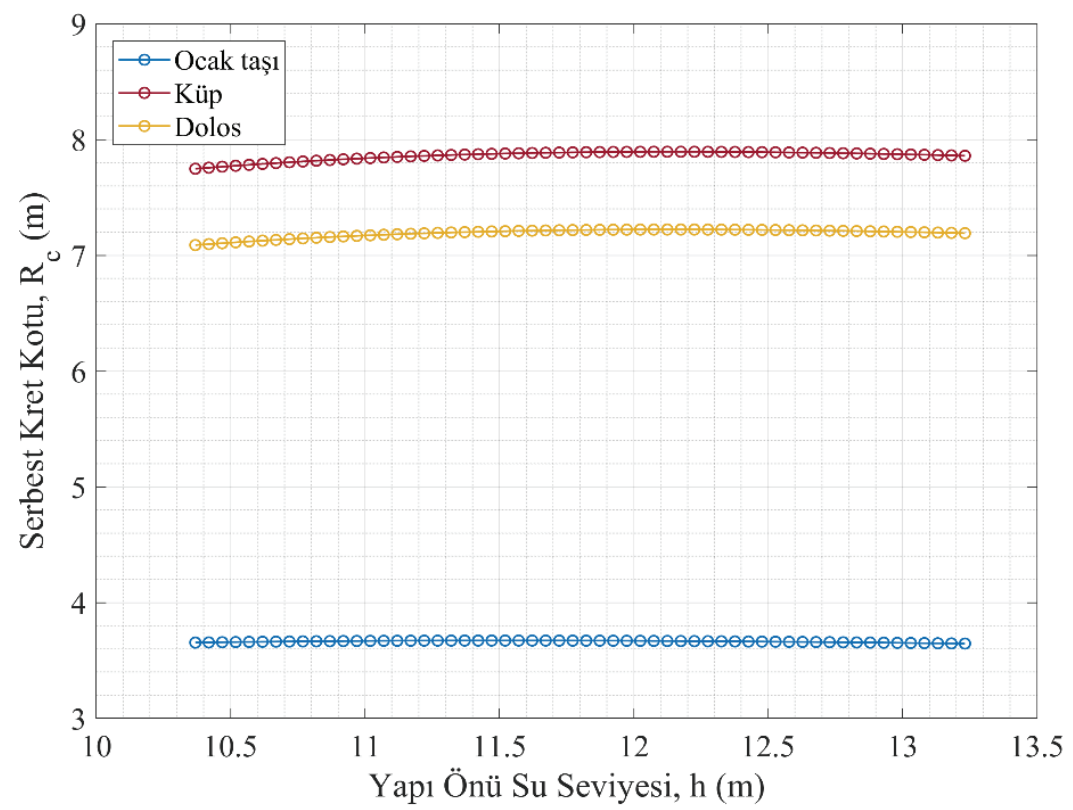

Şekil 5 - Proje A için EurOtop [6] yaklaşımı ile hesaplanan serbest kret kotunun yapı önü su seviyesine göre değişimi

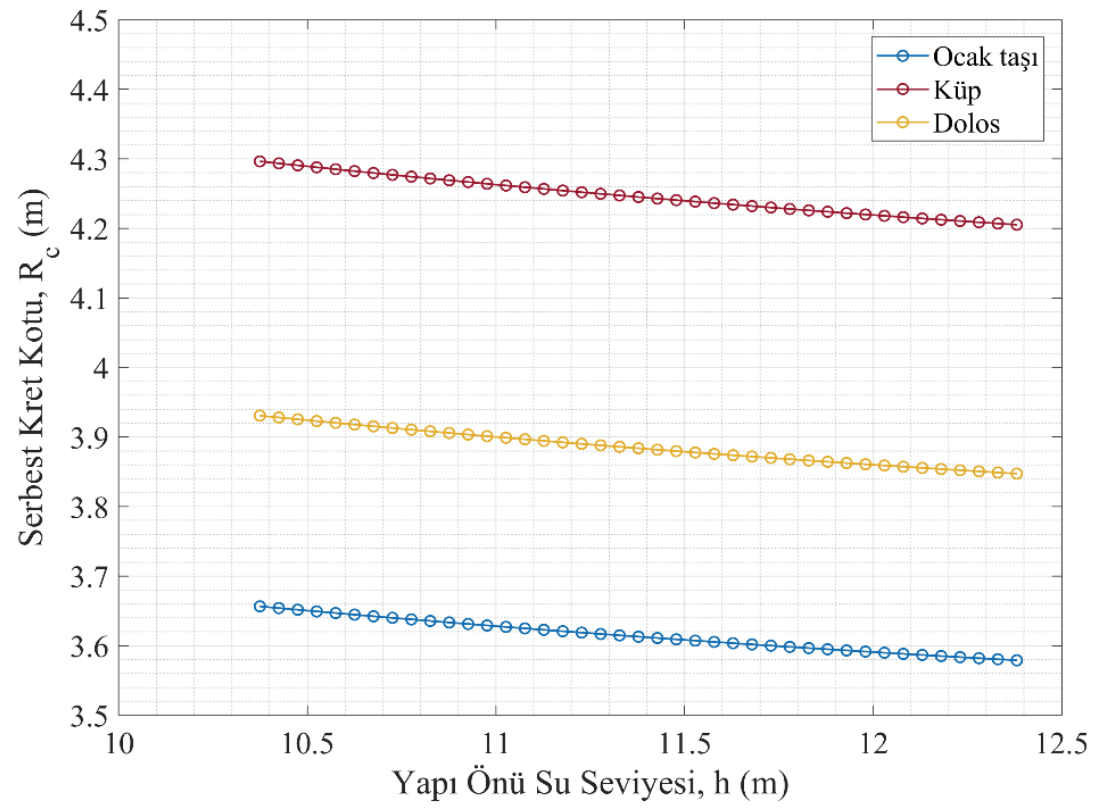

Şekil 6 - Proje B için EurOtop [6] yaklaşımı ile hesaplanan serbest kret kotunun yapı önü su seviyesine göre değişimi 


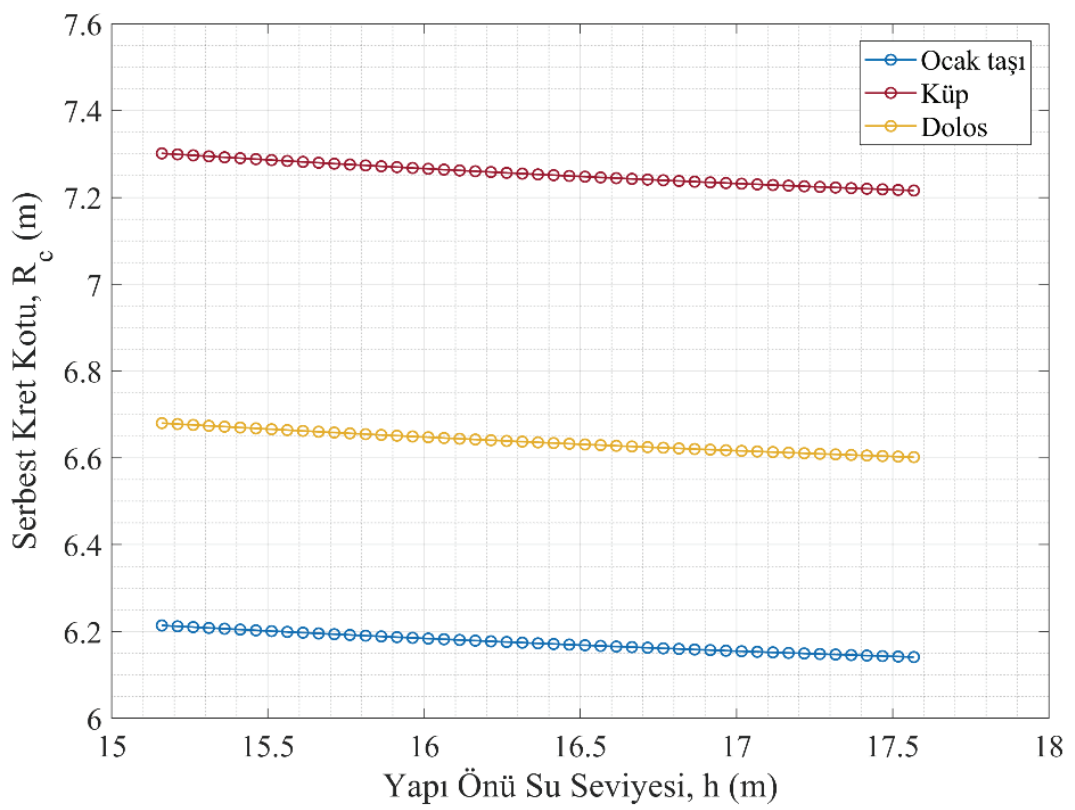

Şekil 7 - Proje C için EurOtop [6] yaklaşımı ile hesaplanan serbest kret kotunun yapı önü su seviyesine göre değişimi

Proje B yöresi için serbest kret kotunun değeri Şekil 6'da verildiği üzere yapı önü su seviyesi arttıkça azalmaktadır. Ancak bu azalma kıyı mühendisliği uygulamaları açısından önemsenmeyecek düzeydedir $(6-8 \mathrm{~cm})$. Bu kesit ve tasarım koşulları için tasarım derinliği yapının ömrü boyunca karşılaşılabilecek herhangi bir su seviyesi olarak alınabilir. Bununla birlikte, Proje A yöresi için yapılan uygulamada da görüldüğü gibi küp beton blokların kullanılması durumunda, izin verilen dalga aşması miktarını sağlayabilmek için dolos beton bloklara ve ocak taşına nazaran daha yüksek serbest kret kotu kullanılması gerekmektedir.

Şekil 7 incelendiğinde, Proje $\mathrm{C}$ yöresinde yapı önü su seviyesi arttıkça serbest kret kotunun değeri önemsenmeyecek düzeyde $(5-6 \mathrm{~cm})$ azaldığı görülmektedir. Dolayısıyla dalga aşması hesaplamalarında bu kesit ve tasarım koşulları için tasarım derinliğinin önemli bir etkisi görülememiştir. Bununla birlikte, Proje A ve Proje B için verilen sonuçlarda da gözlemlendiği gibi serbest kret kotu pürüzlülük katsayısına bağlı olarak en yüksek değerini küp beton bloklar göz önüne alınarak yapılan hesaplamalarda, en düşük değerini ise ocak taşı kullanıldığı durumda almaktadır.

\section{SONUÇLAR}

$\mathrm{Bu}$ çalışmada taş dolgu kıyı koruma yapılarının ekonomik ömürleri boyunca karşılaşabilecekleri kısa ve uzun dönemli ortalama su seviyesi değişikliklerinin yapıların tasarımına ve performansına etkileri deterministik bir yaklaşımla incelenmiştir. $\mathrm{Bu}$ 
incelemede Karadeniz, Ege Denizi ve Akdeniz'de seçilen üç proje alanında örnek uygulamalar yapılmıştır.

$\mathrm{Bu}$ çalışma ile elde edilen sonuçlar ülkemizde kullanılan tasarım esaslarında [1] tasarım derinliğinin bulunması için önerilen yöntemin uluslararası ölçekte yaygın bir şekilde kullanılan tasarım esaslarından [2, 3] farklılığının sebebini ortaya koymaktadır. Çalışmada taş dolgu dalgakıranların koruma tabakalarının tasarımı için en kritik su seviyesinin en yüksek su seviyesi olabileceği gibi, yapının ömrü boyunca karşılaşılabilinecek en düşük su seviyesi ile en yüksek su seviyesi arasındaki herhangi bir değer de olabileceği seçilen proje alanları özelinde AYGM [1] tarafından önerilen Hudson [2] ve CIRIA vd. [3] yaklaşımları için örneklenmiştir. Bu örneklerde seçilen proje alanları için daha düşük su seviyelerinde, daha yüksek su seviyelerine göre \%60'a varan oranda daha büyük taş kütlesi hesaplanmıştır. $\mathrm{Bu}$ durumun temel sebebinin Hudson [2] yaklaşımı için yapı önü su seviyesi yükseldikçe kırılan dalgalar bölgesinden, kırılmayan dalgalar bölgesine geçiş olduğu belirtilmiş; CIRIA vd. [3] tarafından önerilen yaklaşım için ise Van Gent vd. [5] metodundan Van der Meer [4] metoduna geçişin bu farklılığa sebep olduğu ifade edilmiştir. Öte yandan, dalga aşmasına bağlı olarak belirlenen serbest kret kotu değerinin yükselen su seviyesi ile yükselebileceği, sabit kalabileceği veya mühendislik açısından önemsenmeyecek düzeyde azalabileceği EurOtop [6] tarafından verilen ve AYGM [1] tarafından önerilen yaklaşım kullanılarak ortaya konmuştur. Koruma tabakasında kullanılacak taş kütlelerinin hesaplanmasında \%60'a varan oranda farklılıklar görülmesi, AYGM [1] tarafından önerilen tasarım derinliği bulma yönteminin önemini göstermektedir. $\mathrm{Bu}$ sebeple taş dolgu kıyı koruma yapılarının tasarımında yapının ekonomik ömrü boyunca oluşabilecek tüm su seviyelerinin tasarım derinliği belirlenirken göz önünde bulundurulması önerilmektedir.

Son yıllarda yapılan bazı araştırmalarda [36-38] iklim değişikliğinin kıyı koruma yapıları üzerinde yaratacağı olumsuz etkiler vurgulanmakta, özellikle ortalama su seviyesinde yaşanabilecek artışlara bağlı etkilerin giderilebilmesi için kıyı koruma yapılarının iyileştirilmesine yönelik çözümler önerilmektedir. Genel olarak ortalama su seviyesi arttıkça daha kritik tasarım koşulları oluşacağı öngörüldüğünden, ülkemizde de birçok kıyı koruma yapısının iyileştirilmeye ihtiyacı olacağı beklenmektedir. Öte yandan, bu çalışmada gösterilen örnekler, ortalama su seviyesinde gözlenebilecek artışların kıyı koruma yapılarının koruma tabakasında kullanılacak taş boyutlarının belirlenmesi açısından her zaman kritik olmadığını ortaya koymaktadır. Bu sebeple, ülkemizdeki kıyı koruma yapılarının iyileştirilmesine yönelik planlamalar yapının bulunduğu bölgenin ve yapının özgün özelliklerine göre değerlendirilmelidir. Bu değerlendirmelerde iklim değişikliğinin ortalama su seviyesinde yaratabileceği yükselmelerin yanı sıra rüzgâr ve dalga özelliklerinde oluşması beklenen değişimlerin de tartışılması önerilmektedir. Ancak, rüzgâr ve dalga özelliklerinde iklim değişikliğine bağlı değişimler ile ilgili yeteri kadar veri olmadığından, bu çalışmada iklim değişikliği ile ilgili olarak yalnızca ortalama su seviyesinde yaratması beklenen etkiler değerlendirilmiştir.

\section{Semboller}

$\mathrm{D}_{50} \quad$ : Taşların medyan nominal kübik çapı

H : tasarım dalga yüksekliğini 
$\mathrm{H}_{\% 2} \quad$ : Bir firtına için aşılma olasılığı $\% 2$ olan dalgaların yüksekliği

H $\quad$ : Yapı önü su seviyesi

$\mathrm{H}_{1 / 10} \quad$ : Bir firtına boyunca yapı önüne ulaşan dalgaların en yüksek \%10'unun ortalaması

$\mathrm{H}_{\mathrm{s}} \quad$ : Yapı önü belirgin dalga yüksekliği

$\mathrm{H}_{\mathrm{s} 0} \quad$ : Derin deniz belirgin dalga yüksekliği

$\mathrm{K}_{\mathrm{D}} \quad$ : Hudson stabilite katsayısı

M : Taban eğimi

$\mathrm{M}_{50} \quad$ : Ortalama taş kütlesi

$\mathrm{N}$ : Dalga sayıs

Q : İzin verilen birim uzunluktaki dalga aşma debisi

$\mathrm{R}_{\mathrm{c}} \quad$ : Serbest kret kotu

S : Van der Meer hasar parametresi

$\mathrm{S}_{0} \quad$ :Derin deniz pik dalga dikliği

$\mathrm{T}_{\mathrm{m}} \quad$ : Ortalama dalga periyodu

$\mathrm{T}_{\mathrm{m}-1,0}:$ Spektral dalga periyodu

$\alpha \quad$ :Yapı şev açısı

$\alpha_{0} \quad$ :Derin deniz yaklaşma açısı

$\gamma_{\mathrm{b}} \quad$ : Basamaklı yapılar için düzeltme katsayısı

$\gamma_{\mathrm{f}} \quad$ : Pürüzlülük azaltma katsayısı

$\gamma_{\beta} \quad$ : Açıyla gelen dalgalar için düzeltme katsayısı

$\gamma_{\mathrm{v}} \quad$ : Şev sonunda yer alabilecek duvar düzeltme katsayısı

$\Delta \quad$ : Göreceli özgül kütle

$\xi_{\mathrm{k}} \quad$ : Kritik kırılma parametresi

$\xi_{\mathrm{m}} \quad$ : Ortalama dalga periyodu dikkate alınarak hesaplanan kırılma parametresi

$\xi_{\mathrm{m}-1,0}$ : Spektral dalga periyodu dikkate alınarak hesaplanan kırılma parametresi

$\rho_{\mathrm{s}} \quad$ : deniz suyunun özgül kütlesini

$\rho_{\mathrm{t}} \quad$ : taşların özgül kütlesini

\section{Teşekkür}

Önerileriyle bu çalışmaya destek olan Prof. Dr. Ayşen Ergin ve Dr. Işskhan Güler'e; çalışma kapsamında verileri kullanılan danışmanlık projelerinde emeği geçen ODTÜ İnşaat Mühendisliği Deniz Mühendisliği Araştırma Merkezi çalışanlarına teşekkür ederiz. 


\section{EK A: NSW Sayısal Modeli}

NSW sayısal modeli Bölüm 3.2'de yapılan kabuller ile enerji denge denklemi ve doğrusal olmayan sığ su denklemlerini çözmektedir. NSW'nun düzensiz dalgaların sığlaşması ve kırınımının hesaplanabilmesi için çözdüğü ilk denklem olan enerji denge denklemi Karlsson [39] tarafından verilmiştir. Mase [40] dalga kırılması ve dönmesi ile ilgili terimler ekleyerek değiştirdiği enerji denge denkleminin 1-boyutlu hali Denklem A.1'de verilmektedir. Bu çalışmada 1-boyutlu bir çözüm yapıldığından dalga dönmesi ile ilgili terim bu denklemde verilmemiştir. Enerji denge denkleminin sayısal çözümü ileri yönde sonlu farklar yöntemi ile düzensiz batimetri üzerinde 1-boyutlu olarak gerçekleştirilmektedir [29].

$$
\frac{\partial\left(E C_{g} \cos \theta\right)}{\partial x}=D_{b} g \rho
$$

Denklem A.1'de $E$ toplam dalga enerjisini, $C_{g}$ dalgaların grup hızını $(\mathrm{m} / \mathrm{s}), \theta$ x ekseninden saat yönünün tersine olacak şekilde dalga yaklaşma açısını (radyan), $D_{b}$ düzensiz dalga kırılmasından kaynaklı enerji kaybını, $g$ yerçekimi ivmesini $\left(9.81 \mathrm{~m} / \mathrm{s}^{2}\right)$ ve $\rho$ su özgül kütlesini ifade etmektedir $\left(\mathrm{kg} / \mathrm{m}^{3}\right)$. Toplam dalga enerjisi (E) Denklem A.2' de verilmektedir:

$$
E=\frac{\rho g H_{r m s}^{2}}{8}
$$

Denklem A.2'de $H_{r m s}$ kök ortalama kare dalga yüksekliğini göstermektedir. Düzensiz dalga kırılmasından kaynaklı enerji akısındaki kayıp $\left(D_{b}\right)$ Janssen ve Battjes [41] tarafından Denklem A.3'teki şekilde tanımlanmıştır.

$$
\begin{aligned}
& D_{b}=\frac{1}{B} \frac{3 \sqrt{\pi}}{16} f_{p} \frac{H_{r m s}^{3}}{h} \\
& \left\{1+\frac{4}{3 \sqrt{\pi}}\left[\left(\frac{H_{b}}{H_{r m s}}\right)^{3}+\frac{3}{2}\left(\frac{H_{b}}{H_{r m s}}\right)\right] \exp \left[-\left(\frac{H_{b}}{H_{r m s}}\right)^{2}\right]-\operatorname{erf}\left(\frac{H_{b}}{H_{r m s}}\right)\right\}
\end{aligned}
$$

Denklem A.3'te $B$ parametresi 1 olarak kabul edilmekte, $f_{p}$ pik frekansı, erf hata fonksiyonunu ve $H_{b}$ maksimum derinlik tarafından kontrol edilen dalga kırılma yüksekliğini göstermektedir. $H_{b}$ Denklem A.4 ile hesaplanabilmektedir.

$$
H_{b}=\gamma_{b} h
$$

Denklem A.4'te $h$ derinliği $\gamma_{b}$ ise kırılma indisini göstermektedir. Kırılma indisinin doğru olarak belirlenmesi, dalgaların kırılmasından dolayı gerçekleşen enerji kaybını doğrudan etkilediğinden büyük önem taşımaktadır. Bu çalışmada kırılma indisi Camenen ve Larson 
[42] tarafından literatürdeki kırılma indisiyle ilgili birçok çalışmayı ve deneyi inceleyerek ortaya koydukları yöntemle hesaplanmaktadır. Bu yönteme göre kırılma indisi Denklem A.5 ile hesaplanmaktadir.

$$
\gamma_{b}=\frac{0,284}{\sqrt{S_{0}}} \tanh \left[f_{*} \pi \sqrt{S_{0}}\right]
$$

Denklem A.5'te $S_{0}$ derin deniz dalga dikliğini ve $f_{*}$ taban eğimine ve derin deniz dalga dikliğine bağlı ampirik bir fonksiyonu göstermektedir. Derin deniz dalga dikliği bu çalışmada derin deniz belirgin dalga yüksekliğinin derin deniz pik dalga boyuna oranı olarak hesaplanmaktadır. $f_{*}$ fonksiyonu ise Denklem A.6 ile verilmektedir.

$$
f_{*}=a_{1}+a_{2} \sin \left[\frac{\pi}{2}\left(\frac{m}{m_{\max }}\right)^{\alpha}\right]
$$

Denklem A.6'da $a_{1}, a_{2}$ ve $\alpha$ uyum parametrelerini, $m_{\max }$ fonksiyonun değerinin maksimum değerine ulaştığı taban eğimini, $m$ ise gerçek taban eğimini göstermektedir. Uyum parametrelerinden $a_{1}$ 0,87 olarak alınırken, $a_{2}$ Denklem A.7 ve $\alpha$ Denklem A.8 kullanılarak hesaplanmaktadır. $m_{\max }$ değeri ise Denklem A.9 ile verilmektedir.

$$
\begin{aligned}
& a_{2}=0,32+14 S_{0} \\
& \alpha=1+14 S_{0} \quad m \leq m_{\max } \\
& \alpha=-\left(1+20 S_{0}\right) \quad m>m_{\text {max }} \\
& m_{\max }=0,10+1,6 S_{0}
\end{aligned}
$$

NSW sayısal modelinde ortalama su seviyesinde meydana gelen dalga kabarması/alçalması değişikliklerinin hesaplanabilmesi için Denklem A.10 ve Denklem A.11'de verilen 1-boyutlu doğrusal olmayan sığ su denklemleri çözülmektedir.

$$
\begin{aligned}
& \frac{\partial \bar{\eta}}{\partial t}+\frac{\partial}{\partial x}[u(h+\bar{\eta})]=0 \\
& \frac{\partial u}{\partial t}+u \frac{\partial u}{\partial x}+g \frac{\partial \bar{\eta}}{\partial x}+\frac{1}{\rho(h+\bar{\eta})} F_{x}=0
\end{aligned}
$$

Denklem A.10 ve Denklem A.11'de $\bar{\eta}$ ortalama su seviyesi değişimini (m), $u$ x-yönündeki derinlik ortalamalı akım hızını (m/s), $h$ ortalama su seviyesini (m) ve $F_{x}$ su kütlesine dalga 
yayılım gerilmeleri ve yüzey girdapları sebebiyle etkiyen gerilme akısının toplamını göstermektedir. Bu denklemlerde $t$ zamanı göstermekle beraber, denklemler kararlı durum için çözüldügünnden zamana bağlı türevlerin değeri sıfır olarak kabul edilmiştir. Bu çalışma kapsamında 1-boyutlu doğrusal olmayan sığ su denklemleri, taşınım terimi göz ardı edilerek doğrusallaştırılmıştır. Böylece, $\bar{\eta}$ sadece Denklem A.12'de verilen momentum denkleminin çözümü ile bulunmaktadır:

$$
g \frac{\partial \bar{\eta}}{\partial x}+\frac{1}{\rho(h+\bar{\eta})} F_{x}=0
$$

$F_{x}$ terimi Goda [10] tarafından Denklem 13'teki gibi verilmiştir:

$$
F_{x}=\frac{\partial S_{x x}}{\partial x}+\frac{\partial\left(2 E_{s r} \cos ^{2} \theta\right)}{\partial x}
$$

Bu denklemde $S_{x x}$ x-yönündeki gerilme akısını, $E_{s r}$ yüzey girdaplarının kinetik enerjisini, $\theta$ ortalama dalga yaklaşma açısını göstermektedir. $S_{x x}$ Longuet-Higgins ve Stewart [43] tarafından Denklem A.14'deki gibi tanımlanmıştır:

$$
S_{x x}=E\left[n\left(\cos ^{2} \theta+1\right)-0.5\right]
$$

Denklem A.14'te $E$ toplam dalga enerjisini, $n$ ise dalgaların grup hızının dalga hızına oranını göstermektedir. Tajima ve Madsen [44] yüzey girdaplarının kinetik enerjisini $\left(E_{s r}\right)$ şu şekilde tanımlamaktadır:

$$
E_{s r}=\frac{\rho A_{s r} C}{2 T}
$$

Denklem A.15'te $A_{s r}$ yüzey girdaplarının alanını, $C$ dalga süratini ve $T$ dalga periyodunu göstermektedir. Bu çalışmada dalga periyodu olarak pik dalga periyodu $\left(T_{p}\right)$ kullanılmıştır. Kinetik enerjinin düzensiz bir batimetri üzerindeki değişimi, Denklem A.16'da verilen 1boyutlu gelişim denkleminin çözümüyle bulunmaktadır:

$$
\alpha \rho g \frac{\partial\left(m_{0} C_{g} \cos (\theta)\right)}{\partial x}+\frac{\partial\left(E_{s r} C \cos (\theta)\right)}{\partial x}=-\frac{K_{s r} E_{s r} C}{h}
$$

Bu denklemde $\alpha \quad 0$ ve 1 arasında değerler alan enerji transferi katsayısını, $m_{0}$ toplam enerji yoğunluğunu, $K_{s r}$ yüzey girdapları kinetik enerjisinin kayıp oranını ifade etmektedir. $K_{s r}$ Tajima ve Madsen [44] tarafından Denklem A.17 ile verilmiştir: 


$$
K_{s r}=\frac{3}{8}(0,3+2,5 m)
$$

Denklem A.17'de $m$ her bir hesaplama ağı aralığındaki taban eğimini belirtmektedir. Yukarıda verilen tanımlar ile birlikte momentum korunumu denklemi Denklem A.18'te verildiği hali almakta ve bu denklem NSW sayısal modelinde ileriye doğru sonlu farklar yöntemi ile kararlı bir çözüme ulaşana değin tekrarlı olarak çözülmektedir.

$$
g \frac{\partial \bar{\eta}}{\partial x}+\frac{1}{\rho(h+\bar{\eta})}\left[\frac{\partial S_{x x}}{\partial x}+\frac{\partial\left(2 E_{s r} \cos ^{2} \theta\right)}{\partial x}\right]=0
$$

\section{Kaynaklar}

[1] AYGM (Altyapı Yatırımları Genel Müdürlüğü), Kıyı Yapıları Planlama ve Tasarım Teknik Esasları. T.C. Ulaştırma, Denizcilik ve Haberleşme Bakanlığı, Ankara, Türkiye, 2016.

[2] CERC (Coastal Engineering Research Center), Shore Protection Manual. USACE, Vicksburg, Mississippi, ABD, 1984.

[3] CIRIA, CUR, CETMEF. The Rock Manual. The use of rock in hydraulic engineering (2. Bask1). C683, CIRIA, Londra, İngiltere, 2007.

[4] Van der Meer, J.W., Rock Slopes and Gravel Beaches under Wave Attack. Doktora Tezi, Delft Universitesi, Hollanda, 1988.

[5] Van Gent, M.R.A., Smale, A.J., Kuiper, C., Stability of Rock Slopes with Shallow Foreshores. 4. Uluslararası Kıyı Yapıları Konferansı Bildirileri Kitab1, Portland, ABD, 2004.

[6] EurOtop. Manual on wave overtopping of sea defences and related structures. An overtopping manual largely based on European research, but for worldwide application. Van der Meer, J.W., Allsop, N.W.H., Bruce, T., De Rouck, J., Kortenhaus, A., Pullen, T., Schüttrumpf, H., Troch, P. ve Zanuttigh, B., www.overtopping-manual.com. 2016.

[7] Simav, M., Okay, H., Gürer, A., Akçakaya, M., Yılmaz, S., Akça, M., Çakmak, R., Karaböce, B., Sadıkoğlu, E., Doğan, U., Türkiye Yükseklik Sisteminin Modernizasyonu ve Gravite Altyapısının İyileştirilmesi Projesi. TMMOB Harita ve Kadastro Mühendisleri Odası 15. Türkiye Harita Bilimsel ve Teknik Kurultayı, 25-28 Mart 2015, Ankara, 2015.

[8] Reeve, D., Chadwick, A., Fleming, C., Coastal Engineering: Processes, Theory and Design Practice", Spon Press, Taylor \& Francis, 2004.

[9] Alpar, B., Dogan, E., Yüce, H., Altiok, H., Sea Level Changes along the Turkish Coasts of the Black Sea, the Aegean Sea and the Eastern Mediterranean. Med. Marine Science, $1,141-156,2000$. 
[10] Goda, Y., Random Seas and Design of Maritime Structures, 3. Basım. World Scientific, 2010.

[11] SMHI (Swedish Meteorological and Hydrological Institute), Air Pressure and Sea Level. Web Sitesi: https://www.smhi.se/en/theme/air-pressure-and-sea-level-1.12266, En son giriş tarihi: 25 Temmuz 2018, 2018.

[12] Yu, D., Analysis on Impact of the Coriolis Forces on Flow in the Yangtze River Estuary. 3. Çin-Alman Birleşik Kıyı ve Okyanus Mühendisliği Sempozyumu, National Cheng Kung Universitesi, Tainan, November 8-16 2006, 2006.

[13] Suh, K.D., Kim, S-W., Mori, N., Mase, H., Effect of Climate Change on Performancebased Design of Caisson Breakwaters. Journal of Waterway, Port, Coastal and Ocean Engineering, 138(3), 215-225, 2012.

[14] Shimosako, K., Takahashi, S., Reliability Design Method of Composite Breakwater using Expected Sliding Distance. Port and Harbour Research Institute, Ministry of Transport, Yokosuka, Japan, 1998. (Japonca)

[15] Kim, T. M.,, Takayama, T., Computational Improvement for Expected Sliding Distance of a Caisson-type Breakwater by Introduction of a Doubly-truncated Normal Distribution. Coastal Engineering Journal, 45 (3), 387419, 2003.

[16] T.C. Çevre ve Şehircilik Bakanlığı, Türkiye İklim Değişikliği 6. Bildirimi, 2015.

[17] Ozyurt, G., Kirezci, C., Guler, H. G., Baykal, C., Yalciner, A. C., Pelinovsky, E., Zaytsev, A., Kurkin, A., Observations of Extreme Waves at South Coast of Black Sea. IUGG Genel Toplantısı 2015, 22 Haziran-2 Temmuz 2015, Prag, Çek Cumhuriyeti, 2015.

[18] Alpar, B., Doğan, E., Yüce, H., On the Long Term (1935-1976) Fluctuations of the Low Frequency and Main Tidal Constituents and their Stability in the Gulf of Antalya. Turkish Journal of Marine Science 1, 13-22, 1995.

[19] Belokopytov, V., Goryachkin, Y., Sea Level Changes in the Black Sea (1923-1997). Mitchum, Gary (Ed), IOC Çalıştay Raporu, 1999.

[20] Shuisky, Y. D., Implications of the Black Sea Sea Level Rise in Ukraine. SURVAS Bildirileri Kitabı, Hamburg, Almanya, 2000.

[21] Yıldız, H., Demir, C., Mean Sea Level Changes and Vertical Crustal Movements at Turkish Tide Gauges for the Period of 1984-2001. Dikey Kabuk Hareketi ve Deniz Seviyesi Değişimi Çalıştayı, 17-19 Eylül 2002, Toulouse, Fransa, 2002.

[22] Tsimplis, M.N., Josey, S.A., Rixen, M., Stanec, E.V., On the Forcing of Sea Level in the Black Sea. Journal of Geophysical Research, 109, 2004.

[23] Alpar, B., Vulnerability of Turkish Coasts to Accelerated Sea-Level Rise. Geomorphology, 107, 58-63, 2009.

[24] Simav, M., Yıldız, H., Türkezer, A., Lenk, O., Özsoy, E., Sea Level Variability at Antalya and Menteş Tide Gauges in Turkey: Atmospheric, Steric and Land Motion Contributions. Studia Geophysica and Geodaetica, 56, 215-230, 2012. 
[25] Avşar, NB., Jin, S., Kutoglu, H., Gurbuz, G., Sea Level Change along the Black Sea Coast from Satellite Altimetry, Tide Gauge and GPS Observations. Geodesy and Geodynamics, 7 (1), 50-55, 2016.

[26] Vousdoukas, M.I., Mentaschi, L., Voukouvalas, E., Verlaan, M., Feyen, L., Extreme Sea Levels on the Rise along Europe's Coasts. Earth's Future, 5, 304-323, 2017.

[27] Hükümetlerarası İklim Değişikliği Paneli (Intergovernmental Panel on Climate Change, IPCC), Coastal Systems and Low-Lying Areas, AR5 Sentez Raporu. 2014.

[28] USACE (US Army Corps of Engineers), Coastal Engineering Manual Part VI. 28 Eylül 2011 (3. Değişiklik), 2011.

[29] Baykal, C., Two-Dimensional Depth-Averaged Beach Evolution Modelling. Doktora Tezi, ODTÜ, Ankara, Türkiye, 2012.

[30] Baykal, C., Development of A Two-Dimensional Beach Evolution Model. Turkish Journal of Earth Sciences, 23: 215-231., 2014.

[31] Baykal, C., Ergin, A., Güler, I., Two-Dimensional Depth-Averaged Beach Evolution Modelling: Case Study of the Kizilirmak River Mouth, Turkey. Journal of Waterway, Port, Coastal and Ocean Engineering, Vol 140, Issue 3, 2014.

[32] Battjes, J. A., Groenendijk, H. W. Wave Height Distribution on Shallow Foreshores. Coastal Engineering, Vol 40, No. 3, pp. 161-182, 2000.

[33] Hsu, S.A., On the Correction of Land-Based Wind Measurements for Oceanographic Applications. 17. Uluslararası Kıyı Mühendisliği Konferansı Bildirileri Kitabı, 1980.

[34] Ergin, A., Özhan, E. Wave Hindcasting Studies and Determination of Design Wave Characteristics for 15 Regions - Final Report, ODTÜ, Ankara, 1986.

[35] Ergin, A., Yalciner, A.C., Guler, I., Baykal, C., Esen, M., Karakus, H., Fugla Beach Protection and Control Project - Final Report. ODTÜ, Ankara, 2008.

[36] Reeve, D., On the Impacts of Climate Change for Port Design, 26. Uluslararas1 Limanlar ve Deniz Taşımacılığı Konferansı Bildirileri Kitabı, 2010.

[37] Burcharth, H. F., Andersen, T. L., Lara, J. L., Upgrade of Coastal Defence Structures against Increased Loadings caused by Climate Change: A First Methodological Approach. Coastal Engineering, 87, 112-121, 2014.

[38] Burcharth, H. F., Zanuttigh, B., Andersen, T.L., Lara, J.L., vd., Innovative Engineering Solutions and Best Practices to Mitigate Coastal Risk. Coastal Risk and Mananagement in a Changing Climate, Elsevier Inc., 2015.

[39] Karlsson, T., Refraction of Continuous Ocean Wave Spectra. ASCE Bildirileri Kitab1 95 (WW4), 1969.

[40] Mase, H., Multidirectional Random Wave Transformation Model Based on Energy Balance Equation. Coastal Engineering Journal, 43 (4), 317-337, 2001.

[41] Janssen, T. T., Battjes, J. A., A Note on Wave Energy Dissipation over Steep Beaches. Coastal Engineering, 54, 711-716, 2007. 
[42] Camenen, B., Larson, M., Predictive Formulas for Breaker Depth Index and Breaker Type. Journal of Coastal Research, 23(4), 2007.

[43] Longuet-Higgins, M.S., Stewart, R.W., Radiation Stresses in Water Waves; A Physical Discussion with Applications. Deep-Sea Research 11: 529-562, 1964.

[44] Tajima, Y., Madsen, O. S., Modelling Near Shore Waves and Surface Roller. Asya Pasific Kıyıları 2. Uluslararası Konferansı, Makuhari, Chiba, Japonya, 2003. 